\title{
End-of-the-Year Economic Growth and Time-varying Expected Returns
}

Møller, Stig V.; Rangvid, Jesper

\author{
Document Version \\ Accepted author manuscript \\ Published in: \\ Journal of Financial Economics \\ DOI: \\ 10.1016/j.jfineco.2014.08.006 \\ Publication date: \\ 2015 \\ License \\ CC BY-NC-ND
}

Citation for published version (APA):

Møller, S. V., \& Rangvid, J. (2015). End-of-the-Year Economic Growth and Time-varying Expected Returns. Journal of Financial Economics, 115(1), 136-154. https://doi.org/10.1016/j.jfineco.2014.08.006

Link to publication in CBS Research Portal

\section{General rights}

Copyright and moral rights for the publications made accessible in the public portal are retained by the authors and/or other copyright owners and it is a condition of accessing publications that users recognise and abide by the legal requirements associated with these rights.

\section{Take down policy}

If you believe that this document breaches copyright please contact us (research.lib@cbs.dk) providing details, and we will remove access to the work immediately and investigate your claim.

Download date: 26. Apr. 2023

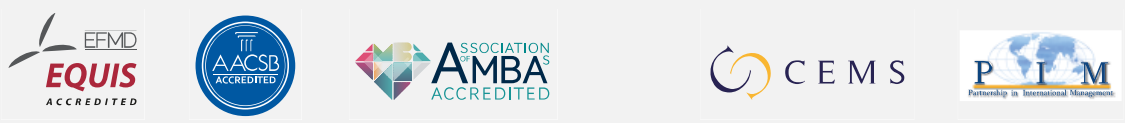




\section{End-of-the-Year Economic Growth and Time-varying Expected Returns}

\section{Stig V. Møller and Jesper Rangvid}

Journal article (Post print version)

CITE: End-of-the-Year Economic Growth and Time-varying Expected Returns. / Møller, Stig V.; Rangvid, Jesper. In: Journal of Financial Economics, Vol. 115, No. 1, 2015, p. 136-154.

DOI: 10.1016/j.jfinec0.2014.08.006

Uploaded to Research@CBS: December 2016

(C) 2016. This manuscript version is made available under the CL-BY-NC-ND 4.0 license http://creativecommons.org/licenses/by-nc-nd/4.0/ 


\title{
End-of-the-year economic growth and time-varying expected returns*
}

\author{
Stig V. Møller $\quad$ Jesper Rangvid ${ }^{\ddagger}$
}

March 2014

\footnotetext{
${ }^{*}$ We thank an anonymous referee, Caio Almeida (WFA discussant), Geert Bekaert, Lasse Bork, Peter Christoffersen, John Cochrane, Hui Guo, Søren Hvidkjær, Ralph Koijen (CEPR ESSFM discussant), Lasse Pedersen, Maik Schmeling, Andreas Schrimpf, Annette Vissing-Jørgensen, Jan Wrampelmeyer (EFA discussant), and participants at many seminars and conferences for comments and suggestions. The paper includes some results from an early paper entitled "The fourth-quarter consumption growth rate: A pure-macro, not-estimated stock return predictor that works in-sample and out-of-sample". Møller acknowledges support from CREATES - Center for Research in Econometric Analysis of Time Series (DNRF78), funded by the Danish National Research Foundation.

${ }^{\dagger}$ CREATES and Department of Economics and Business, Aarhus University, Fuglesangs Allé 4, 8210 Aarhus, Denmark. Phone: (45) 87164825 and e-mail: svm@asb.dk.

${ }^{\ddagger}$ Department of Finance, Copenhagen Business School, Solbjerg Plads 3, 2000 Frederiksberg, Denmark. Phone: (45) 38153615 and e-mail: jr.fi@cbs.dk.
} 


\title{
End-of-the-year economic growth and time-varying expected returns
}

\begin{abstract}
We show that macroeconomic growth at the end of the year (fourth quarter or December) strongly influences expected returns on risky financial assets, whereas economic growth during the rest of the year does not. We document this pattern for many different asset classes, across different time periods, and for US and international data. We also show that movements in the surplus consumption ratio of Campbell and Cochrane (1999), a theoretically well-founded measure of time-varying risk aversion linked to macroeconomic growth, influence expected returns stronger during the fourth quarter than the other quarters of the year. Our findings suggest that expected returns, risk aversion, and economic growth are particularly related at the end of the year where we also expect consumers' portfolio adjustments to be concentrated.
\end{abstract}

Keywords: $\quad$ End-of-the-year (fourth-quarter) economic growth, expected returns, surplus-consumption ratio, consumer confidence.

JEL-classification: E44; G12; G14 


\section{Introduction}

Most financial economists would probably agree that economic growth should matter for expected returns. In a recession, for instance, investors are reluctant to take on risk pushing up expected returns on risky assets (Campbell and Cochrane, 1999). Empirically, it has been difficult to establish a robust link between time-series movements in economic growth and expected returns, however. A forecasting regression of next year's return from the US stock market in excess of the risk-free rate $\left(R^{e}\right)$ on US real seasonally-adjusted GDP growth $\left(G^{G D P}\right)$ of this quarter, using quarterly observations since 1947, illustrates this:

$$
R^{e}=\alpha-2.59 G^{G D P}+\varepsilon, \quad t\left(G^{G D P}\right)=-1.70, \quad \bar{R}^{2}=1.65 \%, \quad T=248 .
$$

In this regression, $t\left(G^{G D P}\right)$ is the Newey-West (1987) adjusted $t$-statistic associated with the coefficient to GDP growth, the estimate for the constant is suppressed as it is unimportant for the point we make here, and $T$ is the number of observations (we are more specific on the details of this regression later in the paper). This result - an insignificant $t$-statistic and a low $\bar{R}^{2}$ - implies that time-series movements in expected excess returns have had no systematic relation to fluctuations in economic growth during the last $60+$ years. Given that the continuous relation between expected returns and economic growth is a fundamental building block of many economic models, the apparent lack of a robust relation is puzzling. ${ }^{1}$

In this paper, we hypothesize that the relation between economic growth and expected returns is stronger at infrequent points in time. Our inspiration for this hypothesis is Duffie and Sun (1990), Lynch (1996), Gabaix and Laibson (2002), Jagannathan and Wang (2007), Bacchetta and van Wincoop (2010), and Abel, Eberly, and Panageas (2007, 2013) who argue that investors adjust their portfolio and consumption decisions at infrequent points in time. As

\footnotetext{
${ }^{1}$ The lack of a robust time-series relation between economic growth and expected aggregate returns is wellknown in the literature. For instance, in their survey, Lettau and Ludvigson (2010, page 625) write: "If such cyclical variation in the market risk premium is present, we would expect to find evidence of it from forecasting regressions of excess returns on macroeconomic variables over business cycle horizons. Yet the most widely investigated predictive variables have not been macroeconomic variables, but instead financial indicators such as equity-valuation ratios that have forecasting power concentrated over horizons longer than the typical business cycle."
} 
an example, Abel, Eberly, and Panageas (2013) show that if there is a small fixed component to transaction costs, the interval between which investors make portfolio allocation decisions becomes constant. It follows that the relation between economic growth and expected returns should be stronger at such infrequent points where the Euler equation binds. We argue that the end of the year is a good candidate for a point in time where the relation between economic activity and expected returns is stronger.

We use the first part of this paper to thoroughly document that end-of-the-year macroeconomic growth rates (growth in real consumption, real GDP, industrial production, employment, capacity utilization, real labor income, etc.) contain a surprisingly large amount of information about expected excess returns over the next year from stocks and bonds, in-sample and out-of-sample, and in the US as well as internationally. As an example, when we pick out the fourth-quarter growth rates of real $\operatorname{GDP}\left(G^{G D P, 4}\right.$ : The growth from the third quarter to the fourth quarter) from the total sample of quarterly GDP growth rates, and use $G^{G D P, 4}$ to predict next calendar year's excess return $\left(R^{e}\right)$, we find:

$$
R^{e}=\alpha-7.48 G^{G D P, 4}+\varepsilon, \quad t\left(G^{G D P, 4}\right)=-4.95, \quad \bar{R}^{2}=15.40 \%, \quad T=62 .
$$

In this regression, the relation between expected returns and fourth-quarter GDP growth is highly significant ( $t$-statistic close to -5 ), and $G^{G D P, 4}$ explains a substantial fraction of the stock return variation $\left(\bar{R}^{2}\right.$ above $\left.15 \%\right)$. Likewise, using fourth-quarter growth in industrial production or real consumption generates $\bar{R}^{2}$ s of $18 \%$ and $16 \%$, respectively. These $\bar{R}^{2}$ s can be compared to the $11 \%$ or so that are generated by the typical variables used in the literature to capture movements in expected returns, such as the dividend-price ratio or the $\widehat{c a y}$ ratio of Lettau and Ludvigson (2001). We also show, and this is the key point in the paper, that the growth rates of macroeconomic variables during the other quarters of the year are not significant predictors of excess returns. This explains why it has been difficult to uncover a robust relation between economic growth and expected returns: The strong information contained by the fourth quarter is difficult to detect from a typical time-series regression of future returns on macroeconomic growth rates using all quarters as, in such a regression, the significant fourth- 
quarter effect gets mixed up with the noisy effects from the other quarters that do not contain systematic information about expected returns.

We show that these results extend to many other settings than the US in-sample equity return situation. For instance, we study out-of-sample predictability. Goyal and Welch (2008) show that traditional variables work poorly out-of-sample in that they generate low or negative out-of-sample $R^{2}$ s. We confirm this. Fourth-quarter economic growth rates, on the other hand, are significant predictors of excess returns out-of-sample with $R^{2}$ s around $10 \%$, even when using vintage data available to the investor in real time. In addition, fourth-quarter economic growth rates predict returns on other portfolios than the aggregate US equity market portfolio, such as returns on portfolios of stocks sorted on book-to-market values and dividend yields, as well as bond returns. We study the robustness of these results through time. In general, fourthquarter economic growth contains more information about expected returns in subsamples since the mid-1940s than commonly-used information variables, such as the dividend-price ratio or the $\widehat{c a y}$ ratio. We focus on quarterly observations in our paper as most macro variables are quarterly. Using monthly observations on industrial production, we show that within the fourth quarter, December growth rates capture a higher fraction of variation in expected returns than November and October growth rates, which makes intuitive sense, as we argue below. Finally, the fourth-quarter growth rate of industrial production in the G-7 countries is a strong predictor of excess returns on the world market portfolio as well as on regional portfolios, such as the European portfolio, the EAFE portfolio (Europe, Australia, and the Far East), and so on, whereas economic growth during the other quarters does not predict returns globally, i.e., the fourth-quarter effect is not just a US phenomenon.

To explain our findings, we study the empirical relation between the surplus consumption ratio of Campbell and Cochrane (1999) and expected returns. Campbell and Cochrane (1999) show theoretically that low surplus consumption ratios in cyclical downturns lead to high risk aversion, which in turn lead to high expected returns, whereas high surplus consumption ratios in cyclical upswings lead to low expected returns. We show empirically that expected returns relate far more to movements in the surplus consumption ratio during the fourth quarter than 
during the other quarters of the year. We also show that fourth-quarter growth in consumer confidence, which we view as an empirical proxy for risk aversion, is a stronger predictor of returns than growth in confidence during the rest of the year.

We view our results of a stronger relation between economic growth, risk aversion (surplus consumption ratio), and expected returns at the end of the year as evidence in favor of the infrequent portfolio adjustment hypothesis where investors are more likely to make investment decisions at infrequent points in time, such as the end of the year, possibly because of information and transaction costs. There are several reasons why the end of the year is special. First, Jagannathan and Wang (2007), page 1625, write that "Investors are more likely to make consumption and portfolio choice decisions at the end of each calendar year because of Christmas and the resolution of uncertainty about end-of-year bonuses and the tax consequences of capital gains and losses". This suggestion is supported by the results provided in Ritter and Chopra (1989) and $\mathrm{He}, \mathrm{Ng}$, and Wang (2004) that investors rebalance their portfolios more significantly at the end of the year. ${ }^{2}$ Second, a considerable literature has shown that economic activity at the end of the year is particularly pronounced. For instance, Barsky and Miron (1989), Beaulieu and Miron (1992), and Beaulieu, MacKie-Mason, and Miron (1992) show that movements in macroeconomic time series are dominated by what they call the "Christmas demand shock". Likewise, Wen (2002) finds that large fluctuations in macroeconomic variables around Christmas generate larger future business cycles fluctuations. This finding makes it likely that investors pay particular attention to economic growth at the end of the year where they are also more likely to make portfolio decisions.

As just mentioned, we view our results as supporting the argument in Jagannathan and Wang (2007) that the end of the year is special. In the "lazy investor" model of Jagannathan and Wang (2007), investors compare the level of consumption at the end of the year with its level at the end of last year, i.e., Jagannathan and Wang (2007) focus on annual growth in consumption from the fourth quarter last year to the fourth quarter this year. In our paper, we focus on quarterly growth (in consumption and many other economic variables) from the

\footnotetext{
${ }^{2}$ It is important that we already early on stress that our findings do not reflect a traditional January effect (Rozeff and Kinney, 1976): We also find strong predictability if we predict returns starting from the second quarter, i.e., excluding the first quarter and therefore excluding January.
} 
third quarter (Q3) this year to the fourth quarter (Q4) this year. We pay special attention to explaining and documenting why we focus on quarterly Q3Q4 economic growth.

Based on the empirical evidence we present, and the theories we rely on, the story in our paper ultimately is as follows: When economic fluctuations at the end of the year are relatively more important for business cycle fluctuations (Wen, 2002) and when investors take current economic performance into account when forming expectations about future returns (Campbell and Cochrane, 1999), which they seem to do to a significant extent at the end of the year (Ritter and Chopra, 1989), i.e., investors are "lazy" (Jagannathan and Wang, 2007) possibly because of information and transaction costs (Abel, Eberly, and Panageas, 2007, 2013), expected returns will be relatively more affected by end-of-the-year economic activity.

\subsection{Related literature}

This paper is related to the literature on infrequent portfolio decisions mentioned above. In particular, our paper is inspired by Jagannathan and Wang (2007), and is therefore also closely related to other papers that build on the work of Jagannathan and Wang (2007), such as Jagannathan, Marakani, Takehara, and Wang (2012), Møller (2008), Da and Yun (2010), and Da, Yang, and Yun (2013). Jagannathan and Wang study static consumption-CAPMs and use annual growth in real consumption from the fourth quarter last year to the fourth quarter this year to price the cross-section of annual excess returns on US stocks. Our focus is different: We study time-variation in expected returns. In addition, we study primarily growth in real macroeconomic variables from the third to the fourth quarter. As mentioned, we pay careful attention to explaining the differences that arise when using third-quarter-to-fourthquarter economic growth to predict returns as compared to using annual fourth-quarter-tofourth-quarter consumption growth in consumption CAPMs.

Our paper is also related to the literature that models time-varying expected returns via time-varying preferences, such as Campbell and Cochrane (1999) and Bekaert, Engstrom, and Grenadier (2010), as we find expected returns to be high during bad economic times. Given that we find this to be the case at the end of the year, our paper is also related to those papers 
that analyze models with seasonal patterns in preferences, such as Miron (1986), Ferson and Harvey (1992), Braun and Evans (1995), and, more recently, Kamstra, Kramer, Levi, and Wang (2011).

This paper builds on the large return-predictability literature (for surveys, see Campbell, 2003; Cochrane, 2007; Lettau and Ludvigson, 2010; Rapach and Zhou, 2013), and, within this literature, more specifically on those papers that deal with the relation between time-series movements in expected returns and macroeconomic variables, such as Cochrane (1991), Lamont (2000), Lettau and Ludvigson (2001), Lustig and Van Nieuwerburgh (2005), Santos and Veronesi (2006), Rangvid (2006), Cooper and Priestley (2009), and Belo and Yu (2013). Our contribution to this literature is to show that one finds strong return predictability by pure macroeconomic variables if focusing on the fourth-quarter growth rate, but not otherwise, thereby showing that there actually is a strong link between movements in business cycle variables and future returns; something the literature has called upon (see footnote 1). Our work is also related to those papers that investigate the relation between consumer confidence and expected returns, such as Charoenrook (2003), Fisher and Statman (2003), Ludvigson (2004), Brown and Cliff (2005), Qui and Welch (2006), Lemmon and Portniaguina (2006), and Schmeling (2009). In relation to this literature, we show that the fourth-quarter change in consumer confidence is a stronger predictor of returns than consumer confidence during the other quarters. This is a new finding in the consumer confidence-expected returns literature.

The rest of the paper proceeds as follows. In the next section, we describe the data we use. In Section 3, we provide comprehensive evidence that the fourth-quarter growth rates of many macroeconomic variables capture movements in expected returns in the US and abroad, across different assets, and in-sample and out-of-sample. In Section 4, we turn to the question of why the fourth-quarter growth rate is such a strong predictor by showing that the surplus consumption ratio influences expected returns stronger during the fourth quarter compared to the rest of the year. A final section concludes. 


\section{Data}

The business cycle variables we focus on are the quarterly growth rates of seasonally adjusted industrial production, real GDP, and real per capita consumption of services and non-durable goods. Later, in Section 3.6, we show that we find similar results to those reported below using many other business cycle variables. By using both national account data (GDP and consumption) and explicit production (industrial production) data, we make sure that our results are not driven by a particular choice here.

Real GDP is directly downloadable and no data transformations have been done (except converting to quarterly growth rates, of course). ${ }^{3}$ As consumption, we use real per capita consumption of non-durables and services, like in Jagannathan and Wang (2007). We refer to that paper for details on data construction and sources. Industrial production is available at a monthly frequency. ${ }^{4}$ We use quarterly averages of the monthly observations to compare with the other macro series, but also show results using the monthly observations.

Quarterly national accounts are available from 1947. In our regressions, we use 1948 as the first observation because we compare the fourth-quarter growth rate with the growth rates of the other quarters, and the first first-quarter growth rate (the change from the fourth to the first quarter) of the national accounts data (GDP and consumption) is the one from 1948, i.e., the growth from 1947:4 to 1948:1. Starting in 1947 for the second, third, and fourth quarter would not change the results to any noteworthy extent. Our last observation is for 2009:4.

For our main results, we use the Center for Research in Security Prices (CRSP) valueweighted index including NYSE, AMEX, and NASDAQ stocks to calculate the returns on stocks. In addition, we show results from predictions of excess returns on the CRSP equalweighted index. We compute excess returns on stocks by subtracting a short Treasury Bill rate from stock returns. In the forecasting regressions, we mainly focus on one-year-ahead excess returns, which we compute year-over-year. We notice that our annual excess returns are for all practical purposes identical to the annual excess returns that, e.g., Kenneth French provides on

\footnotetext{
${ }^{3}$ Data are from St. Louis Fed's FRED database: http://research.stlouisfed.org/fred2/series/GDPC96?cid=106

${ }^{4}$ Data are from St. Louis Fed's FRED database: http://research.stlouisfed.org/fred2/series/INDPRO?cid=3
} 
his homepage; the correlation between his and our excess return series is 0.9991 .

We compare the predictive power of fourth-quarter economic growth with two commonly used predictive variables: The dividend-price ratio, DP (see, e.g., Campbell and Shiller, 1988; Fama and French, 1988, 1989) and the $\widehat{c a y}$-ratio of Lettau and Ludvigson $(2001){ }^{5}$ DP is calculated as the ratio between the CRSP dividends and the CRSP value-weighted stock index. We use the accumulated dividends paid out during the previous twelve months divided by the end-of-the-year value of the CRSP index, i.e., $D P$ is measured at the end of the year. The cointegration residual $\widehat{c a y}$ is the estimated consumption-wealth ratio proposed by Lettau and Ludvigson (2001), and we obtained it at annual frequency from Amit Goyal's website.

\subsection{Summary statistics}

Table 1 provides summary statistics for the predictors we use. The table reports the average quarterly growth rates, standard deviations, and the first-order autoregressive coefficients, and, in the lower part of the table, the correlations between the time series of the fourth-quarter growth rates. $G^{1}$ is the first-quarter growth rate, i.e., the growth rate between the fourth and first quarter, $G^{2}$ the second-quarter growth rate, $G^{3}$ the third-quarter growth rate, and $G^{4}$ is the fourth-quarter growth rate, i.e., the growth rate between the third and the fourth quarter of a year.

The data are seasonally adjusted so there are no particularly notable differences between the summary statistics of the different quarters. But some notable features of the data are that the average growth rates of the per capita consumption series are lower than the average GDP growth rates due to population growth. We also note that the industrial production series is more volatile than the other business cycle variables. This higher volatility of industrial production is also visible from Fig. 1, which shows the time-series behavior of the fourthquarter growth rates together with indications if there is a NBER-defined recession during the fourth quarter of a particular year. Of course, as is also clear from the figure, the Q4-variables

\footnotetext{
${ }^{5}$ We have checked our results against a host of other predictive variables suggested in the literature. Most of them are statistically insignificant when controlling for the fourth-quarter economic growth rate. We focus on $D P$ and $\widehat{c a y}$ as they are among the most popular candidates to predict stock returns in the literature.
} 
reach their lowest values during recessions, i.e., are low during severe economic downturns.

\section{Fourth-quarter economic growth and expected returns}

\subsection{In-sample US equity return predictions}

In this section, we first show in Table 2 the results from regressing US one-year-ahead excess stock returns on the quarterly growth rates of the different macroeconomic variables in-sample, i.e., results from the annual regression:

$$
R_{t+1}^{e}=\alpha+\beta G_{t}^{i}+\varepsilon_{t+1}
$$

where $R_{t+1}^{e}$ is the one-year-ahead excess return on stocks, and $G_{t}^{i}$ is the quarter $i$ growth rate of one of the business cycle variables. For $G^{4}$, the growth from the third to the fourth quarter of a year, the one-year-ahead excess stock return is measured over the calendar year. For $G^{1}$, the one-year-ahead excess stock return is measured from the beginning of the second quarter to the end of the first quarter next year, and so on for $G^{2}$ and $G^{3}$. At the bottom of the table, we show results from using the benchmark variables to predict calendar year returns. For each regression, we report the slope estimate, the Newey-West corrected $t$-value (truncated at lag 2; our results are very robust towards other choices of truncation lags), and the adjusted $R^{2}$-statistic.

We first describe results from predictions of returns on the value-weighted portfolio. The initial point to notice is that all fourth-quarter economic growth rates are strongly significant; the $t$-statistics are -4.88 using consumption, -4.95 using GDP, and -5.74 using industrial production. These are very high (absolute values) $t$-statistics in this kind of regression. For instance, $\widehat{c a y}$ generates a $t$-statistic of 3.65 and the dividend yield a $t$-statistic of 3.07. Likewise, the $\bar{R}^{2}$ s from using the fourth-quarter growth rates are high too: The $\bar{R}^{2}$ s are all above $15 \%$. Among the benchmark variables, $\widehat{c a y}$ generates the highest $\bar{R}^{2}$ of around $12 \%$ - clearly lower than those generated by the fourth-quarter growth rates. The estimated sign on $G^{4}$ is negative, 
as expected, such that a negative (positive) movement in economic growth during the fourth quarter raises (lowers) expected returns. We return to a more detailed interpretation of this sign in Section 4.

The second important aspect to notice from Table 2 is that economic growth during the other quarters does not significantly affect expected returns; only growth during the fourth quarter does.

Table 2 also shows results from predictions of the return on the equal-weighted CRSP portfolio. We show the results obtained using the fourth-quarter growth rates to predict; like for the value-weighted portfolio, the first-, second-, and third-quarter economic growth rates are not significant predictors of future returns on the equal-weighted portfolio. The main take-away is that fourth-quarter economic growth rates predict returns on both small-cap and large-cap firms, as the results for the equally-weighted portfolio are similar to the results for the valueweighted portfolio; if anything, the results are slightly stronger for the equal-weighted portfolio. We show in Section 3.5 that when we concentrate on subsamples of the full sample, though, differences between the predictability of returns on the equal-weighted and the value-weighted portfolios appear.

In the following, we discuss briefly some of the robustness tests we did to verify that our basic in-sample regressions are robust. Afterwards, we provide more thorough discussions on the way we calculate fourth-quarter economic growth (Section 3.2), the use of monthly data (Section 3.3), out-of-sample analyses (Section 3.4), subsamples analyses and analyses of a longer sample (Section 3.5), the use of more variables (Section 3.6), and the use of international data (Section 3.7).

\subsubsection{Timing of returns}

Our results are robust to the timing of the returns we forecast. This is comforting because macroeconomic data are released with a lag. For instance, the final estimates for the fourthquarter national account figures are typically released near the end of March. Hence, we also 
regressed one-year-ahead excess returns from the beginning of the second quarter to the end of the first quarter next year on the Q4-variables. The results are in Table 3, and, as can be seen, they are much in line with those reported in Table 2. Fourth-quarter growth rates are strong predictors of returns, and growth rates during the other quarters generally do not predict returns.

We also did another check of the importance of the timing of returns. In Table 2, we predict returns over different one-year periods, each commencing after the end of the quarter we look at. To make sure that this choice of timing of the returns does not influence our conclusions, we also predicted the same one-year-ahead return, i.e., using both Q1, Q2, Q3, and Q4 economic growth to predict calendar year returns, using both Q1, Q2, Q3, and Q4 economic growth to predict Q1-Q1 returns, etc. We find that Q4 economic growth rates predict Q4-Q4 (calendar year) returns, Q1-Q1 returns, marginally Q2-Q2 returns, but not Q3-Q3 returns. None of the other quarterly economic growth rates predict returns at any point in time. Hence, only Q4 economic growth rates contain information about expected returns.

\subsubsection{Predicting using all observations}

We mentioned in the Introduction that a standard predictive regression using all observations (not exclusively end-of-the-year observations of economic growth) of one-year-ahead excess returns on the GDP growth rate of this quarter generates insignificant $t$-values and low $R^{2}$ s. We showed the results for GDP in the Introduction. We can now show results when using growth in industrial production $\left(G_{t}^{I P}\right)$ and growth in consumption $\left(G_{t}^{C}\right)$ :

$$
\begin{aligned}
& R_{t, t+4}^{e}=\alpha-1.54 G_{t}^{I P}+\varepsilon_{t, t+4}, \quad t\left(G_{t}^{I P}\right)=1.82, \quad \bar{R}^{2}=2.54 \% . \\
& R_{t, t+4}^{e}=\alpha-5.70 G_{t}^{C}+\varepsilon_{t, t+4}, \quad t\left(G_{t}^{C}\right)=1.87, \quad \bar{R}^{2}=1.99 \% .
\end{aligned}
$$

Generally, these results show that when using all observations, it is difficult to verify a firm and strong relation between economic growth and expected returns on the aggregate stock market.

We do not want to claim that there cannot be subperiods where one will find significant 
results. For instance, Chen (1991) finds that lagged growth in industrial production predicts returns during the 1954-1986 period. On the other hand, Rapach, Rangvid, and Wohar (2005) investigate data from many countries, including the US, and find that industrial production is generally not significantly related to future returns. Rodriguez, Restoy, and Pena (2002) also study international data and in most cases find no significant relation between future returns and growth in industrial production in the typical time series regression using all observations. The point in our paper is that one sees more clearly the predictive power of economic growth when focusing on the end-of-the-year growth rate.

\subsubsection{Long-horizon cumulative returns}

The predictive power of Q4-variables builds up over the next year, and then declines for cumulative returns over more than one year. We see this from Table 4 that shows results from standard long-horizon regressions $R_{t, t+h}^{e}=\alpha+\beta G_{t}^{I P}+\varepsilon_{t, t+h}$, where $R_{t, t+h}^{e}$ is the excess return obtained over $h$ quarters. To save space, we show in Table 4 only the results based on using industrial production to predict. The results we find using the other business cycle variables are similar to the results shown in Table 4. We find that Q4-variables are strong predictors of medium-term (up to one year) returns, but not longer-term returns: When predicting twoyear cumulative returns, the $R^{2}$ drops from its $17.93 \%$ at the one-year horizon to only $8.55 \%$, and three-year cumulative returns are not even predictable to a significant extent. This is different from results in the literature using persistent predictors such as the dividend yield. The $R^{2}$ s and $t$-statistics from regressions using persistent predictors mechanically increase with the horizon, and several papers discuss the potential biases that arise in long-horizon predictive regressions when the predictor is persistent (see, e.g., Valkanov, 2003; Boudoukh, Richardson, and Whitelaw, 2008). Q4-variables are not persistent predictors as shown in Table 1 and seen from Fig. 1. For this reason, the fact that the $\bar{R}^{2}$ rises with the horizon up to $h=4$ reflects that Q4-variables predict the returns of different quarters of the year, and not just one quarter of the year. We also see from the table that none of the other quarters' growth rates predict returns at any horizon. Finally, in the lower part of Table 4, we show results from predictions 
of long-horizon returns on the equal-weighted portfolio. Like in Table 2, there are no particular differences to the results from the value-weighted portfolio.

\subsubsection{Real vs. nominal economic growth}

We study real economic growth and its relation to expected returns. Real activity and inflation are related, though, even if the direction of the relation depends upon the kind of shocks that drive the economy. According to Keynesian demand-based explanations, real activity and inflation are positively related (if there is low demand in the economy, firms reduce the rate at which they increase wages and prices), whereas supply shocks can cause a negative relation between inflation and real activity (an oil-price shock could increase inflation but lower economic activity). Aruoba and Diebold (2010), e.g., show that the relation between inflation and real activity indeed depends upon the underlying shocks driving the economy.

Given that the relation between inflation and real activity depends upon the underlying shocks driving the economy, and that this relation is most likely time-varying and dependent on the relative importance of demand and supply shocks, it is perhaps not too surprising that our results are not driven by inflation. In more detail, Table 5 shows that we find no systematic relation between inflation and future returns. ${ }^{6}$ We also notice that even if only few of the coefficients are significant, the signs to the estimated coefficients are all negative, in accordance with the findings in Fama and Schwert (1977) and Fama (1981) of a negative relation between inflation and expected returns for the pre-oil crisis period.

If we use nominal GDP to predict returns, we reestablish that the fourth-quarter growth rate is a strong predictor of returns (we find a slope coefficient of -6.20 , a $t$-statistic of -4.49 , and an $\bar{R}^{2}$-statistic of $\left.16.55 \%\right)$. We conclude from these exercises that it is real economic activity during the fourth quarter that influences expected returns, and not so much inflation,

\footnotetext{
${ }^{6}$ In Table 5, we show results using two measures of inflation; quarterly growth in the GDP price deflator and quarterly growth in the Consumer Price Index (CPI). In Table A1 in the Internet Appendix, we show that the results are robust towards using inflation calculated as annual changes in the relevant price indexes. In addition, in the Internet Appendix, we also show results using the Personal Consumption Expenditure (PCE) index and core measures of the CPI and PCE. No matter what price index we use, and no matter whether we calculate inflation using quarterly or annual growth rates, the results mentioned in the text and appearing from Table 5 are robust.
} 
and therefore nominal economic growth, in itself.

\subsubsection{Other US portfolios and bonds}

We downloaded dividend-yield sorted portfolios and book-to-market sorted portfolios from Ken French's homepage. The overall finding is that Q4 growth in industrial production is a very strong predictor of the whole cross-section of stocks, with high $t$-statistics and $R^{2}$ s. These results are in Table A2 in the Internet Appendix accompanying our paper.

We also looked at returns from bonds. Fama and French (1989) were the first to suggest examining movements in expected returns on both stocks and bonds across the business cycle to see whether different risky asset classes behave similarly to a movement in a forecasting variable. We use the Fama-Bliss data to calculate the returns on bonds. The results are in Table A3 in the Internet Appendix. We find that the fourth-quarter economic growth rates contain significant information about movements in expected returns on bonds, and that economic growth rates during the other quarters of the year generally give insignificant regression results. Like for stocks in Table 2, the coefficient estimates on the Q4-variables in the bond-predicting regressions are negative, i.e., a negative shock to a Q4-variable increases expected returns on bonds and stocks.

\subsubsection{Statistical issues with return predicting regressions}

$D P$ and $\widehat{c a y}$ are persistent variables; the $\mathrm{AR}(1)$ coefficient of $D P$ is 0.90 and that of $\widehat{c a y}$ 0.72. From Stambaugh (1999), it is well-known that such persistence influences the inference in predictive regressions. Building on the work of Stambaugh (1999), Amihud and Hurvich (2004) and Amihud, Hurvich, and Wang (2009) provide a simple augmented regression method to bias adjust the predictive coefficient and test hypotheses. Using their procedure, we find that $D P$ becomes borderline insignificant (bias adjusted $t$-statistic equal to 1.94 ), whereas $\widehat{c a y}$ remains significant with a slightly smaller $t$-statistic (bias adjusted $t$-statistic equal to 2.92). Given the low persistence of $G^{4}$ (as shown in the "AR1" rows in Table 1), on the other hand, it is not surprising that the effect of the bias correction on the significance of $G^{4}$ is virtually 
non-existing.

\subsection{Measurement of fourth-quarter economic growth}

As mentioned in the Introduction, our paper is related to Jagannathan and Wang (2007), Da and Yun (2010), and Da, Yang, and Yun (2013) who also look at fourth-quarter growth rates. They study annual (Q4Q4) fourth-quarter-to-fourth-quarter (as well as December-to-December) growth in consumption and its relation to the cross-sectional variation in contemporaneous mean returns, whereas we focus on the quarterly growth rate of many macro variables from the third to the fourth quarter (Q3Q4) and future returns. In this section, we explain why we focus on quarterly growth rates when we predict returns.

In Table 6, we show results from regressions using the annual growth rates of GDP, consumption, and industrial production to predict one-year-ahead returns. The results reveal that the annual fourth-quarter growth in consumption (Q4Q4) is a strong predictor of returns, and that annual first-, second-, and third-quarter consumption growth rates are not. In addition, annual fourth-quarter growth in GDP or industrial production does not predict returns. Moving the returns that are predicted one quarter ahead, i.e., using the same timing as in Table 3 , confirms that the annual fourth-quarter growth in consumption is a strong predictor of returns, whereas annual consumption growth during the other quarters, as well as annual growth in GDP and IP during any of the quarters, does not predict returns. Taken together, these results confirm the findings in Jagannathan and Wang (2007), Da and Yun (2010), and Da, Yang, and Yun (2013) that annual fourth-quarter consumption growth contains special asset pricing information.

The Q3Q4 consumption growth rate is strongly positively correlated with the Q4Q4 consumption growth rate. Indeed, the correlation between the two measures of fourth-quarter consumption growth is 0.67 . This high correlation suggests that the two measures to some extent capture common information about expected future returns. We now investigate empirically which of the two measures of fourth-quarter growth contains the most predictive power for future returns. In Table 7, we show results from regressions using, in the same regression, 
the quarterly fourth-quarter growth rate (Q3Q4) and the annual fourth-quarter growth rate (Q4Q4) to predict returns. The table shows results from forecasting the one-year-ahead excess stock return using three sets of regressors: 1) Q3Q4 together with Q4Q4, 2) Q4Q4 together with Q3Q4 ${ }^{\perp}$, which is the part of Q3Q4 that is orthogonal to Q4Q4, and 3) Q3Q4 together with Q4Q4 ${ }^{\perp}$, which is the part of Q4Q4 that is orthogonal to Q3Q4.

Comparing the results of the regression where we use both series unadjusted (left-hand side of Table 7) with the results in Table 2 where we use only Q3Q4 consumption growth, we see in Table 7 that Q3Q4 is significant, whereas Q4Q4 is not, and that the $R^{2}$ is not higher than the one in Table 2 where we only use Q3Q4 consumption growth. When we include Q4Q4 together with Q3Q4 $4^{\perp}$, both series are significant (middle panel). In contrast, when we include Q3Q4 together with Q4Q4 ${ }^{\perp}$, only Q3Q4 is significant (right-hand side panel). Basically, these results imply that when it comes to predicting returns, there is strong and independent information in the quarterly Q3Q4 fourth-quarter consumption growth rate, over and above the information already contained by the annual Q4Q4 consumption growth rate, whereas the annual Q4Q4 consumption growth rate contains only little information about expected returns not already included in the Q3Q4 consumption growth rate.

One could be concerned that the predictive power of Q3Q4 economic growth is partly driven by noise. Considering this issue, we extract the first principal component of the Q3Q4 growth rates of real GDP, real consumption, and industrial production. This first principal component contains the common fluctuations of the three series. Regressing future returns on this principal component generates a very high $t$-statistic $(-7.65)$ and an $\bar{R}^{2}$ of $21.78 \%$. In other words, the systematic component of the quarterly fourth-quarter series is strongly related to one-year-ahead returns.

To sum up the conclusions from this section, we found that (i) the annual Q4Q4 growth in consumption is a strong predictor of returns, (ii) annual Q4Q4 growth in other macro variables does not predict returns, (iii) the quarterly Q3Q4 and the annual Q4Q4 growth rates are highly correlated, and (iv) the major fraction of information about future returns is contained by the quarterly Q3Q4 growth rate. For this reason, we focus on quarterly fourth-quarter growth rates 
in this paper. In Section 4, we return to the economic interpretation of these results.

\subsection{Monthly observations}

We focus on quarterly observations in our paper as most macro variables are available at a quarterly frequency only. Within the fourth quarter, however, December is probably "special" due to Christmas, New Year, and end-of-year features such as tax filings, bonuses, etc. ${ }^{7}$

Industrial production is available at a monthly frequency going back far in time. To evaluate the monthly evidence, we show in Table 8 results from regressions using monthly growth rates of industrial production to predict one-year-ahead excess returns. There are two clear findings: First, the months in the fourth quarter are all special as October, November, and December growth rates all predict both the value- and the equal-weighted portfolio, whereas the other months do not predict returns (September predicts the equal-weighted portfolio but not the value-weighted, though). Second, December contains more predictive power than November and October (and any other month) as coefficient estimates, absolute $t$-statistics, and $R^{2}$ s are all higher using December growth rates to predict. This evidence suggests that a large part of the quarterly action we document in this paper is due to the December growth rate as one would intuitively expect given December's special role in the calendar year. November and October also contain information, possibly partly due to days such as Thanksgiving and Black Friday Shopping in November and economic activities preceding the end-of-the-year events.

With the monthly industrial production data, we can check some of our results in other dimensions. For instance, instead of calculating our quarterly growth rates of industrial production based on quarterly averages, we can calculate them based on end-of-quarter values, such that, e.g., the fourth-quarter growth rate is calculated as (Dec-Oct)/Oct, with "Dec" respectively "Oct" being industrial production in December respectively October. These results are in Table A4 in the Internet Appendix. We find that using end-of-quarter values generate even stronger results than using quarterly averages. Our results for quarterly industrial production

\footnotetext{
${ }^{7}$ We mentioned in the Introduction to this paper that Barsky and Miron (1989) refer to the special business cycle feature of the fourth quarter as a "Christmas demand shock", Wen (2002) examines the "business cycle effects of Christmas", and Jagannathan and Wang (2007) also point to the turn of the year as something special.
} 
are thus robust with respect to different ways of calculating quarterly growth rates.

\subsection{Out-of-sample predictability}

Goyal and Welch (2008) show that returns might be predictable in-sample, but difficult to predict out-of-sample. Goyal and Welch (2008) also show that the main reason for the poor out-of-sample performance of many predictor variables is that predictive regressions are plagued by estimation instability.

There are two features that can cause out-of-sample forecasts using macroeconomic variables to differ from in-sample forecasts. First, in out-of-sample forecasts, the coefficients in the predictive model might change over time compared to the assumption of constant predictive coefficients in in-sample forecasts. Second, the time series available today might be different from the ones available in real time due to data revisions. Where parameter instability is the usual concern in out-of-sample tests (Goyal and Welch, 2008), the issue of data revisions is special to macroeconomic variables. The issue of data revisions is also treated differently in different studies. For instance, in the seminal paper of Lettau and Ludvigson (2001), they use the today-available (and thus revised) consumption series in their out-of-sample tests, whereas Cooper and Priestley (2009) use two measures of the output gap in their analysis: One (the one that they primarily focus on in their analysis) based on real-time vintage industrial output, and one based on today-available and hence revised GDP.

To be on the safe side, we present results using both kinds of macroeconomic series. As our first step, we follow Lettau and Ludvigson (2001) and use the today-available revised series. Of course, this analysis is not representative for how a real-time investor could have performed because of data revisions. The analysis will, though, illustrate how sensitive the forecast performance is towards allowing for time-varying forecast parameters. To investigate how a real-time investor could have performed, we show in a second step that our results are robust to using real-time vintage data.

Our out-of-sample forecasting procedure follows standard practice, so we refer to Appendix 
B in the Internet Appendix for details. Here we just mention that our out-of-sample period is 1975-2009, i.e., we use the 1948-1974 for the initial estimation, and that we test for significant out-of-sample predictive power using three tests: Clark and McCracken's (2001) ENC-NEW statistic, McCracken's (2007) MSE-F statistic, and the adjusted procedure recommended in Clark and West (2007), labeled $t(N W)$ in the tables.

\subsubsection{Today-available data}

Given that final estimates for the national account data are released during March, ${ }^{8}$ we predict returns from the beginning of the second quarter of the year to the end of the first quarter next year to better reflect the situation of a real-time investor. ${ }^{9}$ In Table 9 , upper panel, we show results from out-of-sample predictions using the today-available and thus revised data. Table 9 shows that Q4-variables are strong predictors of excess returns also out-of-sample. The out-of-sample (OOS) $R^{2}$ s are generally around $10 \%$ (9.75\% using consumption and up to $12.57 \%$ using GDP), and the $E N C-N E W$, the $M S E-F$, and the $t(N W)$ test statistics all indicate statistically significant out-of-sample predictability. These results are in stark contrast to the Goyal and Welch (2008) results that we illustrate in the lower part of Table 9, where we use $D P$ and $\widehat{c a y}$. In spite of its extended use in the literature, $D P$ does not generate significant out-of-sample predictability, and in fact predicts worse than the historical mean as seen via the negative OOS $R^{2}$ s. $\widehat{c a y}$ generates a positive OOS $R^{2}$, but $\widehat{c a y}$ is an estimated regressor, i.e., there is some degree of look-ahead bias involved in the construction of $\widehat{c a y}$ (Guo, 2009 discusses this). In addition, the OOS $R^{2}$ s that the Q4-variables generate are considerably higher than the OOS $R^{2}$ that $\widehat{c a y}$ generates.

Table 9 shows results using fourth-quarter growth rates. Using growth rates of other quarters generate results like the in-sample results in Table 2: It is only the fourth-quarter growth rate that predicts returns out-of-sample; economic growth during the other quarters does not.

\footnotetext{
${ }^{8}$ Advance, preliminary, and final estimates for the previous fourth quarter are typically released near the end of January, February, and March, respectively.

${ }^{9}$ We have also used calendar year returns in this setting. The results do not change significantly compared to those in Table 9 .
} 
The right panel in Table 9 shows the results obtained when predicting returns on the equalweighted portfolio out-of-sample. It is apparent that small-cap stocks are even more predictable ( $R^{2} \mathrm{~s}$ are even higher) out-of-sample; we find OOS $R^{2}$ s around $20 \%$ - these are very high out-ofsample $R^{2} \mathrm{~s}$ in light of the Goyal and Welch findings, summarized here via the results obtained using $D P$ and $\widehat{c a y}$. Given that the out-of-sample predictions are done over the period from 1975 and onwards, this indicates that there are differences in the extent to which it is possible to predict returns on large-cap stocks and small-cap stocks during the last couple of decades. In Section 3.5, we investigate this in more detail.

\subsubsection{Vintage data}

A real-time practitioner who uses economic growth during the fourth quarter to improve his forecast of excess stock return faces the potentially important concern that annual revisions take place each summer, and comprehensive revisions take place at irregular intervals. To examine the extent to which the out-of-sample results are sensitive to announcement delays and data revisions, we construct a real-time data set based on vintage data from the ALFRED database at the Federal Reserve Bank of St. Louis. The real-time data set consists of vintages spanning from March 1975 to March 2009, and the data observations from each vintage start in 1948. For instance, the March 1995 vintage contains data from 1948 to 1994. Each vintage incorporates the latest data revisions. We assume that the real-time practitioner uses the final estimates from each vintage - available near the end of March - to make forecasts of $R_{t+1}^{e}$, with $R_{t+1}^{e}$ again being the return obtained from April 1 to March 31 the year after.

We show results from the out-of-sample tests using vintage data in Table $9 .^{10}$ The point to stress from this table is that economic growth during the fourth quarter is also in real time a convincing and significant predictor of excess returns out-of-sample: The OOS $R^{2}$ s are between approximately nine and twelve percent for the value-weighted portfolio (and between ten and twenty percent for the equal-weighted portfolio), and the null hypotheses of equal forecasting power of the restricted and unrestricted models are strongly rejected. The OOS $R^{2}$ s are also

\footnotetext{
${ }^{10}$ Real-time vintage GDP data are not available for the 1975-1992 period in the ALFRED database. For this reason, the table only reports results using vintage data for industrial production and consumption.
} 
considerably higher than those of the benchmark variables. In other words, even if using realtime data, fourth-quarter economic growth rates predict returns better than other commonly used predictors do out-of-sample and also significantly better than the historical mean that Goyal and Welch (2008) report is difficult to "beat".

\subsubsection{Quality of data}

With the vintage data, we can also investigate whether early releases of fourth-quarter data are "superior" in terms of their precision/quality. If this was the case, it would be rational for investors to put relatively more emphasis on fourth-quarter economic data when judging the outlook for financial markets. Hence, we calculated the average "errors" in the data by comparing the average revisions of fourth-quarter economic data (comparing first-release data with the revised data available now) with the average revisions of first, second, and third quarter economic data. Basically, the average revisions are more or less of the same sizes across the different quarters. Hence, it is not simply the quality of the data in the fourth quarter that makes the fourth quarter special.

\subsubsection{Measuring fourth-quarter growth}

We redid our out-of-sample forecasts using annual fourth-quarter-to-fourth-quarter (Q4Q4) growth to predict returns. Like the results for the in-sample data in Section 3.2, these results revealed that the quarterly fourth-quarter growth rate (Q3Q4) predicted returns better out-ofsample compared to the annual Q4Q4 growth. Indeed, the Q4Q4 consumption growth predicted excess returns on the equal-weighted portfolio out-of-sample (OOS $R^{2}=6.7 \%$, which can be compared to the $12.5 \%$ shown in Table 9), but did not predict the return on the value-weighted portfolio. Annual Q4Q4 GDP and industrial production growth did not significantly predict excess returns out-of-sample. Hence, also in out-of-sample investigations, Q3Q4 growth rates predict returns better than annual Q4Q4 growth rates, even if the annual Q4Q4 consumption growth rate also predicts (equal-weighted) returns. 


\subsection{Longer data, subsample analysis, and rolling estimations}

The out-of-sample results have revealed that returns on both the value-weighted and the equal-weighted portfolios have been predictable in real time. To investigate the stability of our results in further detail, we present in this section results from rolling regressions using 40 years in each estimation. We also go back further in time to check the robustness in that dimension. As mentioned, quarterly GDP, consumption, etc. are available since 1947, but industrial production data are available back to 1919 from St. Louis Fed's FRED database. Therefore, we focus in this section on the fourth-quarter growth rate in industrial production. We have CRSP return data since 1927, i.e., this is our starting year. We compare with results from using $D P$ and $\widehat{c a y}$ as predictors (long-term $\widehat{c a y}$ data are available in Lustig and Van Nieuwerburgh, 2005). We show in Fig. 2 coefficient estimates, $t$-statistics, and $R^{2}$ s from rolling regressions of excess returns on the predictors. ${ }^{11}$ Results for the value-weighted portfolio are shown in the left-hand column and results for the equal-weighted portfolio in the right-hand column.

The overall finding is that the fourth-quarter industrial production growth rate has been more related to expected returns than traditionally-used variables, such as DP and the $\widehat{c a y}$ ratio, in particular since the mid-1940s. Estimating over the 1940-1980 period, the absolute $t$-statistics and $R^{2}$ s are considerably higher using $G^{I P, 4}$ compared to using $D P$ and $\widehat{c a y}$. Estimating over the 1950-1990 period, for example, the $t$-statistic using $G^{I P, 4}$ is above 6 (in absolute value) and thereby considerably higher than the $t$-statistic we obtain using $D P$ or $\widehat{c a y}$. Estimating over later subsamples, the predictive power of $G^{I P, 4}$ remains significant, whereas, at the end of the sample, $D P$ is not significantly related to the return on the value-weighted portfolio. For the equal-weighted portfolio, $\widehat{c a y}$ is not significant during any of the subsamples, whereas $G^{I P, 4}$ is.

The predictive power for subsamples ending before the early 1970s is less impressive for any of the three variables, and in particular for $\widehat{c a y}$. In other words, it has been difficult to capture

\footnotetext{
${ }^{11}$ We have multiplied the coefficients and $t$-values obtained using $G^{I P, 4}$ with -1 in order to facilitate comparison with the other coefficient estimates and $t$-values.
} 
movements in expected returns before the early 1940s, as also noticed elsewhere; see, e.g., Chen (2009).

We conclude that $G^{I P, 4}$ has generally been a significant and robust predictor of excess returns on both the equal- and the value-weighted portfolio since 1947, especially compared to traditionally used predictor variables. In particular, $\widehat{c a y}$ does not predict returns on the equalweighted market portfolio during any subsample, while $D P$ does not predict the value-weighted return during recent subsamples. $G^{I P, 4}$, on the other hand, has significantly affected expected returns during the last $60+$ years. In addition, the estimates of the coefficient on $G^{I P, 4}$ are rather stable, whereas the coefficient estimates on $D P$ fluctuate more over time. This also explains why $G^{I P, 4}$ is a significant predictor out-of-sample, as shown in the preceding section.

\subsection{Many more variables}

Our main point in this paper is that macroeconomic growth during the fourth quarter predicts returns strongly. In this section, we show that we obtain the same results using many more macroeconomic variables than industrial production, GDP, or consumption. We have checked these findings using the change in the output gap (either estimated from a quadratic trend model as in Cooper and Priestley, 2009, or as the difference between GDP and potential GDP as calculated by the Congressional Budget Office), the change in the investment-capital ratio of Cochrane (1991), the change in the housing-collateral ratio of Lustig and Van Nieuwerburgh (2005), nonfarm employment growth, labor income growth, changes in the capacity utilization rate (total industry), nonresidential investment growth, changes in the civilian unemployment rate, changes in average weekly hours in manufacturing, changes in overtime hours, etc., etc.

We show in Table 10 results using the quarterly growth rates of some of these variables to predict returns. We find that Q4-growth of all the business cycle variables we look at are strong predictors of excess returns. During the other quarters there are no such clear and systematic effects. ${ }^{12}$ Our main finding in the paper thus extends across a large range of macroeconomic

\footnotetext{
${ }^{12}$ We use value-weighted returns in Table 10 . Using equal-weighted returns, the results are generally even slightly stronger than the already strong results in Table 10.
} 
variables.

\subsection{International evidence}

Fourth-quarter, and only fourth-quarter, growth rates predict returns not only in the US but also world-wide. To show this, we regress one-year-ahead excess returns in US dollars (stock returns in USD minus the US risk-free rate) from the MSCI World, MSCI World excl. US, MSCI EAFE (Europe, Australia, and the Far East), and MSCI Europe index on quarterly growth rates of industrial production. We use two measures of industrial production to predict these global returns: Quarterly growth rates of G7 industrial production and an equal-weighted series of quarterly growth rates of industrial production in Australia, Belgium, France, Germany, Japan, Italy, Netherlands, Sweden, Switzerland, the U.K., and the US. ${ }^{13}$ The sample period is 1970-2009.

The results are in Table 11: We find a clear and strong global Q4 effect. Looking at the results for the world-market portfolio first, we see that - exactly like the US results in Table 2 first-quarter, second-quarter and third-quarter growth rates are insignificant predictors of future returns and generate negative $\bar{R}^{2}$ s, whereas fourth-quarter growth rates are highly significant predictors with $t$-statistics above three in absolute values and $\bar{R}^{2}$ s being either $6.63 \%$ (using the G7 series) or $8.61 \%$ (using equal-weighted growth rates from even more countries). Finally, we notice that the sign to the fourth-quarter growth rate is consistently estimated: In all regressions, a negative movement in the Q4 growth rate of industrial production increases next year's expected return.

Looking at returns from a global portfolio without US returns (results for "World excl. US“), we find similar kinds of results, i.e., fourth-quarter growth rates significantly predict returns, whereas growth rates of other quarters do not. The same is found when looking at returns from Europe, Australia, and the Far East, and when looking at Europe on its own.

\footnotetext{
${ }^{13}$ For robustness, we also used the principal component of the national industrial production series, and we calculated a series using the same countries but excluding the US for which we already know it works, as shown in the previous tables (to see whether the US drives the results). The results were not qualitatively affected. Likewise, instead of capital market weighted returns, we used GDP weighted returns. Again, the results were qualitatively unaffected.
} 
Our conclusion is that it is not only US Q4 variables that predict US returns; indeed, the same finding goes through around the world.

\section{Why does fourth-quarter economic growth capture move- ments in expected returns?}

We now turn to explanations for the predictability patterns that we have documented in the previous section. We base our explanation on a combination of two theories: The theory that expected returns vary countercyclically over time and the theory that portfolio decisions are made at infrequent points in time.

To fix ideas, recall that variation over time in expected excess returns must satisfy the basic no-arbitrage condition (Cochrane, 2005):

$$
E_{t}\left(R_{t+1}^{e}\right) \approx \gamma_{t} \operatorname{cov}_{t}
$$

where $\gamma_{t}$ is risk aversion and $\operatorname{cov}_{t}$ is the conditional covariance between consumption growth and returns. Campbell and Cochrane (1999) specify a habit-persistence model in which the level of risk aversion $\gamma_{t}$ is a function of economic growth implying that $\gamma_{t}$ becomes state-dependent and time-varying because economic growth varies over time. A key feature of this model is that high economic growth leads to low risk aversion and therefore low expected returns. The model therefore generates a negative relation between economic growth and expected returns (as we have found empirically). For this reason, we investigate the model below. We describe how we apply the model of Campbell and Cochrane (1999) in more detail in Section 4.1, where we also describe our results, and in Appendix $\mathrm{C}$ in the Internet Appendix.

To explain why the relation between economic growth, risk aversion, and expected returns is stronger at year-end, we recognize that there is a recent prominent literature (mentioned in the Introduction to our paper) that argues that investors most likely do not make consumption and investment decisions continuously, for instance because of information and transaction 
costs. Instead, this literature argues that investors are more likely to make consumption and investment decisions at infrequent points in time. Similarly to Jagannathan and Wang (2007), we argue that there are good reasons to expect consumers to make investment decisions primarily at the end of the year. These reasons include the Christmas demand shock (Barsky and Miron, 1989), business cycle effects of Christmas (Wen, 2002), end-of-the-year portfolio rebalancing (He, $\mathrm{Ng}$, and Wang, 2004), etc., i.e., the special cultural and institutional features that characterize the end of the year.

The habit-persistence theory of Campbell and Cochrane (1999) implies that economic growth at the time of decision making influences consumers' risk aversion, and hence expected returns, and the infrequent portfolio adjustment theory of Abel, Eberly, and Panageas (2013) and Jagannathan and Wang (2007) implies that the relation between economic growth, risk aversion, and expected returns should be stronger at infrequent points in time which we (and Jagannathan and Wang, 2007) argue could be the end of each calendar year. In the following, we test in two ways our hypothesis that the relation between economic growth, risk aversion, and expected returns is stronger at year-end. First, we extract the surplus consumption ratio of Campbell and Cochrane (1999). We show that the surplus consumption ratio mainly predicts returns at the end of the year. Second, we use consumer confidence as an empirical proxy for risk aversion and study the relation between growth in consumer confidence and future returns. We show that fourth-quarter growth in consumer confidence predicts returns stronger than growth in confidence during the rest of the year. We view our finding that both consumer confidence and the surplus consumption ratio of Campbell and Cochrane (1999) have a stronger relation to expected returns at the end of the year as supporting evidence of our suggested explanation.

As mentioned earlier in the paper, we are inspired by Jagannathan and Wang (2007) in our focus on economic activity at the end of the year. The "lazy investor" model of Jagannathan and Wang (2007) implies that investors compare consumption at the end of the year with consumption at the end of last year, i.e., annual consumption growth. In our paper, we focus on growth in consumption and other economic variables from the third quarter to the fourth. In Section 3.2, we demonstrated the differences that empirically arise when using annual Q4Q4 
growth rates instead of quarterly Q3Q4 growth rates. In Section 4.4, we mention some of the additional differences that exist between the framework of Jagannathan and Wang (2007) and our own.

\subsection{Surplus consumption ratio}

In Campbell and Cochrane (1999), risk aversion is given by $\gamma_{t}=\gamma / S_{t}$, such that timevariation in risk aversion is driven by time-variation in the surplus consumption ratio, $S_{t}$, which then in the end generates time-variation in expected returns. We study in this section whether expected returns react more to changes in the surplus consumption ratio at certain points in time, such as at the end of the year.

In Campbell and Cochrane (1999), the $\log$ surplus consumption ratio $s_{t}=\log \left(S_{t}\right)$ develops over time according to:

$$
s_{t+1}=(1-\phi) \bar{s}+\phi s_{t}+\lambda\left(s_{t}\right) v_{t+1},
$$

where $\bar{s}$ is the steady-state value of $s_{t}, \phi$ determines the persistence of $s_{t}, \lambda\left(s_{t}\right)$ is a nonlinear function of $s_{t}$, and $v_{t+1}$ is the period $t+1$ shock to consumption growth. Thereby, shocks to consumption growth determine how the surplus consumption ratio develops over time implying that time-variation in economic growth will determine time-variation in expected returns. In addition, period $t$ shocks to consumption growth influence period $t$ values of the surplus consumption ratio, i.e., risk aversion and economic growth is related at each point in time. What we want to test is whether there is a closer empirical link between risk aversion (the surplus consumption ratio) and expected returns at the end of the year.

We follow Campbell and Cochrane (1999) closely when computing the surplus consumption ratio, i.e., we use the same parameter values as Campbell and Cochrane and measure consumption as expenditures on nondurables and services. We describe briefly the procedure used to generate $S_{t}$ in Appendix $\mathrm{C}$ in the Internet Appendix.

We show in Table 12 results from regressions of one-year-ahead excess returns on the level of surplus consumption ratio (Panel A) and changes in the surplus consumption ratio (Panel B). 
The results in Panel A reveal that expected returns react mainly to the surplus consumption ratio during the fourth quarter and less so, or not, during the other quarters. In more detail, we find that expected returns on the value-weighted portfolio respond more (coefficient, $t$-statistic, and $R^{2}$ are larger) to movements in the fourth-quarter surplus consumption ratio compared to the other quarters. For the equal-weighted portfolio, only Q4 surplus consumption predicts returns significantly. When we look at changes in the surplus consumption ratio (Panel B), fourth-quarter changes predict both equal- and value-weighted returns, whereas changes during the other quarters do not affect expected returns.

Given the influence of the Campbell and Cochrane article, it is noteworthy that fourthquarter movements in the surplus consumption ratio affect expected returns more than movements during the other quarters of the year. We recognize, however, that the surplus consumption ratio is an extracted variable, depending for instance on chosen parameter values. ${ }^{14}$ To investigate more broadly whether there is a stronger relation between feelings towards the economic situation, and therefore feelings towards taking on risk, and expected returns during the fourth quarter, we investigate in the next section consumer confidence.

\subsection{Consumer confidence and expected returns}

It is intuitive that consumer confidence should be related to risk aversion (Qiu and Welch, 2006; Lemmon and Portniaguina, 2006), possibly via the relation between financial wealth and risk aversion (Brav, Constantinides, and Geczy, 2002; Malloy, Moskowitz, and VissingJørgensen, 2009; Wachter and Yogo, 2010): ${ }^{15}$ If consumers feel less confident with respect to their consumption possibilities, they will probably also be more averse against taking on financial risk. Hence, we investigate in this section the relation between consumer confidence and expected returns.

The University of Michigan and the Conference Board provide reasonably long time-series of

\footnotetext{
${ }^{14}$ We have experimented with other reasonable parameter values than the ones used in Campbell and Cochrane (1999). Our results are robust.

${ }^{15}$ One of the questions in the University of Michigan's consumer survey is whether consumers "feel better or worse off financially".
} 
consumer sentiments. Ludvigson (2004) in detail discusses the construction of the two measures, their differences, and their relative merits. To be on the safe side, we report results using both series. The University of Michigan data are available for the 1960:1-2009:4 period and the Conference Board data for the 1967:1-2009:4 period. The Conference Board data are seasonally adjusted, whereas the University of Michigan data are not. We seasonally adjust the University of Michigan data using the X12 procedure in order for both series to be seasonally adjusted.

Several papers have studied whether consumer confidence in itself predicts aggregate market returns, see, e.g., Ludvigson (2004), Charoenrook (2003), and Schmeling (2009). ${ }^{16}$ The general finding in these papers is that the regression coefficient is negative such that low (high) confidence today predicts high (low) future returns.

In Table 13, we show results from regressions of excess returns on growth in consumer confidence during the different quarters, i.e., from regressions like $R_{t+1}^{e}=\alpha+\beta \Delta \operatorname{Con} f_{t}^{i}+\varepsilon_{t+1}$, where Conf refers to consumer confidence, and the superscript $i$ refers to quarter $i$. We find that growth in consumer confidence during the fourth quarter generally influences expected returns, whereas growth during the other quarters does not. We also see that fourth-quarter growth in consumer confidence is only a marginal predictor of the value-weighted returns, but is a strong predictor of the equal-weighted returns. Consumer confidence at the end of the year thus predicts in particular small-cap stocks. Consumer confidence during the other quarters does not predict returns. Our finding that a large fraction of the predictive power of consumer sentiments reported in earlier studies is concentrated to the fourth quarter gives an interesting new perspective to the existing literature on consumer sentiments and expected returns.

\subsection{Discussion of turn-of-the-year effects in portfolios flows}

We argue that economic growth influences risk aversion which then again influences expected returns, and that investors make infrequent investment decisions such that the relation between economic growth, risk aversion, and expected returns is more pronounced at year-end. It is

\footnotetext{
${ }^{16}$ Lemmon and Portniaguina (2006) find that consumer confidence forecasts the size premium, but not the value or momentum premiums. Lemmon and Portniaguina do not predict the excess return on the market portfolio.
} 
beyond the scope of the present paper to study determinants of portfolio flows more broadly. It is relevant, however, briefly to discuss the evidence on turn-of-the-year effects in flows and trading patterns.

There is ample evidence that there are turn-of-the-year effects in turnover and trading patterns of financial assets; see, e.g., Ritter and Chopra (1989), He, Ng, and Wang (2004), Hu, McLean, Pontiff, and Wang (2013) for evidence on turn-of-the-year trading patterns of institutional investors; Dyl (1977), Poterba and Weisbenner (2001), and Ivoković, Poterba, and Weisbenner (2005) for evidence on tax-motivated trading of (retail) investors at the turn of the year; and Gallant, Rossi, and Tauchen (1992) for evidence of generally higher trading volume around the turn of the year. Flows to and from mutual funds are also characterized by strong turn-of-the-year patterns. For instance, Kamstra, Kramer, Levi, and Wermers (2013), Table 1, show that $72 \%$ of total annual taxable capital gain distributions from mutual funds are paid out in December. Farinella and Koch (2000) show that there are marked turn-of-the-year effects in flows to and from money market mutual funds.

To illustrate turn-of-the-year effects in mutual fund flows, we show in Figure 3 net new cash flows to money market and equity mutual funds in January together with the average flow during the other months of the year (the data have been kindly provided by the Investment Company Institute and span the 1984-2009 period). ${ }^{17}$ The figure shows that net new inflows to mutual funds are particularly pronounced during January, implying that investors in particular make investments and savings decisions around the turn of the year, i.e., that investment decisions are made infrequently. It also seems likely that the large January inflow reflects reinvestments of year-end capital gain and dividend distributions, investments of the parts of year-end bonuses that are saved, and tax-motivated investments influenced by the end of the preceding tax year, i.e., the special cultural and institutional features that characterize the end of the year.

Fig. 3 shows data for mutual funds. We believe it will be an interesting avenue for future research to investigate further the relation between turn-of-the-year net portfolio flows and endof-the-year economic growth, studying flows more broadly, different types of investors (retail

\footnotetext{
${ }^{17}$ Looking separately at flows to money market and equity funds, respectively, reveals that the pattern appearing from Fig. 3 is present for both types of funds, but more pronounced for money market funds.
} 
and institutional), etc. It will also be interesting to test hypotheses regarding these flows more thoroughly in order to distinguish between different effects (retail vs. institutional investor behavior, tax-motivated flows vs. other forms of flows, etc.), but such exciting investigations are outside the scope of the present paper. The point here is to say that the existing literature and the evidence provided in Figure 3 indicate that there is a lot of portfolio rebalancing around the turn of the year, which at least indicates that some investors make portfolio allocations infrequently.

\subsection{Discussion of quarterly vs. annual growth rates}

Our paper is related to Jagannathan and Wang (2007) who match annual returns with contemporaneous annual Q4Q4 growth in consumption. We focus on annual returns but predict with quarterly growth rates. We showed empirically in Section 3.2 that the quarterly Q3Q4 macroeconomic growth rates generally contain more information about expected future returns than the annual Q4Q4 growth rates, with the important caveat that annual Q4Q4 consumption growth rates also predict returns (though to a lesser extent than the quarterly Q3Q4 consumption growth rates). But what is the economic intuition that investors are comparing data at a quarterly horizon for yearly decision variables? We discuss this issue briefly in this section.

First, it is relevant to note that even if we focus on annual returns in our paper, we showed in Table 4 that fourth-quarter (Q3Q4) economic growth predicts returns also at other horizons. In the model of Campbell and Cochrane (1999), economic growth matters for future returns but the model does not specify any particular return-forecasting horizon. We believe it is intuitive that the surplus consumption ratio (which is determined by quarterly economic growth) has a larger impact on annual returns when investment decisions are taken primarily at the end of the year, i.e., once a year, but the model does not restrict the impact to be on annual returns only. In contrast, Jagannathan and Wang (2007) do not study return predictability, but study a consumption CAPM in which the consumption growth horizon should match the return horizon, i.e., if one studies annual returns, the model specifies that one should use annual consumption growth. There is no such restriction in Campbell and Cochrane (1999) when it 
comes to return predictability. This is one reason why Jagannathan and Wang (2007) focus on annual consumption growth, whereas our set-up does not restrict us to do so.

Another, more empirically inspired, reason for looking at quarterly economic growth is based on the results in Wen (2002). Wen (2002) shows that the Q3Q4 economic growth rate has business cycle effects, i.e., quarterly Q3Q4 economic growth has effects on economic activity that last longer than one quarter. In this sense, Q3Q4 growth is an important news event as it affects the future business cycle. In light of Wen's (2002) findings, it is understandable that fourth-quarter (Q3Q4) economic growth can have effects on returns spanning longer than one quarter. In addition, we speculate that if investors take the most recent economic news into account when rebalancing portfolios by the end of the year, then Q3Q4 or November-December growth might capture better the current stage of the business cycle compared to Q4 economic activity in relation to Q4 economic activity the previous year. This could be one reason why quarterly Q3Q4 economic growth generally predicts returns to a larger extent than annual Q4Q4 growth, as Section 3.2 showed.

Finally, in the US when economic growth figures are published, it is the quarterly growth rate that is published and receives attention. ${ }^{18}$ Given that Q3Q4 economic growth also predicts returns after the official figures have been released (Table 3), it seems plausible that the published quarterly growth rate matters more for expected future returns, also at longer horizons.

\section{Conclusion}

Our story in the paper is as follows. We find that negative (positive) movements in economic growth during the fourth quarter strongly predict high (low) future excess returns. We find this for bonds, many kinds of stock portfolios (aggregate and characteristics-sorted portfolios) in the US in-sample and out-of-sample, and for global stock portfolios. We also find that the surplus consumption ratio, a theoretically well-founded measure of risk aversion linked to economic

\footnotetext{
${ }^{18}$ As an example, the press release from the Bureau of Economic Analysis on January 30, 2013, read: "Real gross domestic product - the output of goods and services produced by labor and property located in the United States - decreased at an annual rate of 0.1 percent in the fourth quarter of 2012 (that is, from the third quarter to the fourth quarter)."
} 
growth, mainly affects expected returns during the fourth quarter, as does growth in consumer confidence. We argue that our results are supportive of models based on infrequent portfolio adjustments.

Taken together, the findings in the paper suggest a special role of end-of-the-year economic growth for the time-series properties of asset prices, opening up a number of areas in the intersection between finance and macroeconomics that call upon further examination. 


\section{References}

Abel, A., Eberly, J., Panageas, S., 2007. Optimal inattention to the stock market. American Economic Review 97, 244-249.

Abel, A., Eberly, J., Panageas, S., 2013. Optimal inattention to the stock market with information costs and transactions costs. Econometrica 81, 1455-1481..

Amihud, Y., Hurvich, C. , 2004. Predictive regressions: A reduced-bias estimation method. Journal of Financial and Quantitative Analysis 39, 813-841.

Amihud, Y., Hurvich, C., Wang, Y., 2009. Multiple-predictor regressions: Hypothesis testing. Review of Financial Studies 22, 413-434.

Aruoba, S., Diebold, F., 2010. Real-time macroeconomic monitoring: Real activity, inflation, and interactions. American Economic Review 100, 20-24.

Bacchetta, P., van Wincoop, E., 2010. Infrequent portfolio decisions: A solution to the forward discount puzzle. American Economic Review 100, 870-904.

Barsky, R., Miron, J., 1989. The seasonal cycle and the business cycle. Journal of Political Economy 97, 503-534.

Beaulieu, J., Miron, J., 1992. A cross country comparison of seasonal cycles and business cycles. Economic Journal 102, 772-788.

Beaulieu, J., MacKie-Mason, J., Miron, J., 1992. Why do countries and industries with large seasonal cycles also have large business cycles? Quarterly Journal of Economics 107, 621-656.

Bekaert, G., Engstrom, E., Grenadier, S., 2010. Stock and bond returns with moody investors. Journal of Empirical Finance 17, 867-894.

Belo, F., Yu, J., 2013. Government investment and the stock market. Journal of Monetary Economics 60, 325-339

Boudoukh, J., Richardson, M., Whitelaw, R., 2008. The myth of long-horizon predictability. Review of Financial Studies 21, 1577-1605.

Braun, R. and Evans, C., 1995. Seasonality and equilibrium business cycle theories. Journal of Economic Dynamics and Control 19, 503-531.

Brav, A., Constantinides, G., Geczy, C., 2002. Asset pricing with heterogeneous consumers and limited participation: Empirical evidence. Journal of Political Economy 110, 793-824.

Brown, G., Cliff, M., 2005. Investor sentiment and asset valuation. Journal of Business 78, 405-440. 
Campbell, J, 2003. Consumption-based asset pricing. In: Constantinides, G., Harris, M., Stulz, R. (Ed.), Handbook of the Economics of Finance, North Holland, Amsterdam, pp. 803-887.

Campbell, J., Cochrane, J., 1999. By force of habit: A consumption based explanation of aggregate stock market behavior. Journal of Political Economy 107, 205-251.

Campbell, J., Shiller, R., 1988. The dividend-price ratio and expectations of future dividends and discount factors. Review of Financial Studies 1, 195-208.

Charoenrook, A., 2003. Does sentiment matter? Unpublished working paper. Vanderbilt University.

Chen, N., 1991. Financial investment opportunities and the macroeconomy. Journal of Finance $46,529-554$.

Chen, L., 2009. On the reversal of dividend and return predictability: A tale of two periods. Journal of Financial Economics 92, 128-151.

Clark, T., McCracken, M., 2001. Tests of forecast accuracy and encompassing for nested models. Journal of Econometrics 105, 85-110.

Clark, T., West, K., 2007. Approximately normal tests for equal predictive accuracy in nested models. Journal of Econometrics 138, 291-311.

Cochrane, J., 1991. Production-based asset pricing and the link between stock returns and economic fluctuations. Journal of Finance 46, 209-237.

Cochrane, J., 2005. Asset Pricing. Princeton University Press.

Cochrane, J., 2007. Financial markets and the real economy. In: Mehra, R. (Ed.), Handbook of the Equity Premium, North Holland, Amsterdam, pp. 237-325.

Cochrane, J., Piazzesi, M., 2005. Bond risk premia. Journal of Political Economy 95, 138-160.

Cooper, I., Priestley, R., 2009. Time-varying risk premiums and the output gap. Review of Financial Studies 22, 2801-2833.

Da, Z., Yun, H., 2010. Electricity consumption and asset prices. Unpublished working paper. University of Notre Dame.

Da, Z., Yang, W., Yun, H., 2013. Houshold production and asset prices. Unpublished working paper. University of Notre Dame.

Duffie, D., Sun, T., 1990. Transactions costs and portfolio choice in a discrete-continuous time setting. Journal of Economic Dynamics and Control 14, 35-51.

Dyl, E., 1977. Capital gains taxation and year-end stock market behavior, Journal of Finance $32,165-175$. 
Fama, E., 1981. Stock returns, real activity, inflation, and money. American Economic Review $71,545-565$

Fama, E., French, K., 1988. Dividend yields and expected stock returns. Journal of Financial Economics 22, 3-25.

Fama, E., French, K., 1989. Business conditions and expected returns on stocks and bonds. Journal of Financial Economics 25, 23-49.

Fama, E., Schwert, W., 1977. Asset returns and inflation. Journal of Financial Economics 5, $115-146$.

Farinella, J., Koch, T., 2000. Seasonal patterns in money market mutual funds. Review of Quantitative Finance and Accounting 14, 261-276

Ferson, W., Harvey, C. 1992. Seasonality and consumption-based asset pricing. Journal of Finance 47, 511-552.

Fisher, K., Statman, M., 2003. Consumer confidence and stock returns. Journal of Portfolio Management, 115-127.

Gabaix, X., Laibson, D., 2002. The 6D bias and the equity premium puzzle. NBER Macroeconomics Annual 16, 257-312.

Gallant, R., Rossi, P., Tauchen, G., 1992. Stock prices and volume. Review of Financial Studies $5,199-242$.

Goyal, A., Welch, I., 2008. A comprehensive look at the empirical performance of equity premium prediction. Review of Financial Studies 21, 1455-1508.

Guo, H., 2009. Data revisions and out-of-sample stock return predictability. Economic Inquiry 47, 81-97.

He, J, Ng, L, Wang, Q, 2004. Quarterly trading patterns of financial institutions. Journal of Business 77, 493-509.

Hu, G., McLean, R.D., Pontiff, J., Wang, Q., 2013. The year-end trading activities of institutional investors: Evidence from daily trades. Review of Financial Studies, forthcoming.

Ivković, Z., Poterba, J., Weisbenner, S., 2005. Tax-motivated trading by individual investors. American Economic Review 95, 1605-1630.

Jagannathan, R., Marakani, S., Takehara, H, Wang, Y., 2012. Calendar cycles, infrequent decisions, and the cross section of stock returns. Management Science 58, 507-522.

Jagannathan, R., Wang, Y., 2007. Lazy investors, discretionary consumption, and the crosssection of stock returns. Journal of Finance 62, 1623-1661. 
Kamstra, M., Kramer, L., Levi, M., Wang, T., 2011. Seasonally varying preferences: Theoretical foundations for an empirical regularity. Unpublished working paper. University of Toronto.

Kamstra, M., Kramer, L., Levi, M., Wermers, R., 2013. Seasonal Asset Allocation: Evidence from Mutual Fund Flows. Unpublished working paper. University of Toronto.

Lamont, O., 2000. Investment plans and stock returns. Journal of Finance 55, 2719-2745.

Lemmon, M., Portniaguina, E., 2006. Consumer confidence and asset prices: Some empirical evidence. Review of Financial Studies 19, 1499-1529.

Lettau, M., Ludvigson, S., 2001. Consumption, aggregate wealth and expected returns. Journal of Finance 55, 815-849.

Lettau, M., Ludvigson, S., 2010. Measuring and modeling variation in the risk-return tradeoff. In: Ait-Sahalia, Y., Hansen, L. (Ed.), Handbook of Financial Econometrics, North Holland, Amsterdam, pp. 617-690.

Ludvigson, S., 2004. Consumer confidence and consumer spending. Journal of Economic Perspectives $18,29-50$.

Lustig, H., Van Nieuwerburgh, S., 2005. Housing collateral, consumption insurance and risk premia: An empirical perspective. Journal of Finance 60, 1167-1219.

Lynch, A., 1996. Decision frequency and synchronization across agents: Implications for aggregate consumption and equity return. Journal of Finance 51, 1479-1497.

Malloy, C., Moskowitz, T., Vissing-Jørgensen, A., 2009. Long-run stockholder consumption risk and asset returns. Journal of Finance 64, 2427-2479.

McCracken, M., 2007. Asymptotics for out-of-sample tests of causality. Journal of Econometrics 140, 719-752.

Miron, J., 1986. Seasonal fluctuations and the life cycle-permanent income model of consumption. Journal of Political Economy 94, 1258-1279.

Møller, S., 2008. Consumption growth and time-varying expected returns. Finance Research Letters 5, 129-136.

Newey, W., West, K., 1987. A simple, positive semidefinite, heteroskedasticity and autocorrelation consistent covariance matrix. Econometrica 55, 703-708.

Poterba, J., Weisbenner, S., 2001. Capital gains tax rules, tax loss trading, and turn-of-the-year returns. Journal of Finance 56, 353-368.

Qui, L., Welch, I., 2006. Investor sentiment measures. Unpublished working paper. Brown University. 
Rangvid, J., 2006. Output and expected returns. Journal of Financial Economics 81, 595-624.

Rapach, D., Rangvid, J., Wohar, M., 2005. Macro variables and international stock return predictability. International Journal of Forecasting 21, 137-166.

Rapach, D., Zhou, G., 2013. Forecasting stock returns. In: Elliott, G., Timmermann, A. (Ed.), Handbook of Economic Forecasting, North Holland, Amsterdam, pp. 328-383.

Ritter, J., Chopra, N, 1989. Portfolio rebalancing and the turn-of-the-year effect. Journal of Finance 44, 149-166.

Rodriguez, R. Restoy, F., Pena, J., 2002. Can output explain the predictability and volatility of stock returns? Journal of International Money and Finance 21, 163-182.

Rozeff, M., Kinney, W., 1976. Capital market seasonality: The case of stock returns. Journal of Financial Economics 3, 379-402.

Santos, T., Veronesi, P., 2006. Labor income and predictable stock returns. Review of Financial Studies 19, 1-44.

Schmeling, M., 2009. Investor sentiment and stock returns: Some international evidence. Journal of Empirical Finance 16, 394-408.

Stambaugh, R., 1999. Predictive regressions. Journal of Financial Economics 54, 375-421.

Valkanov, R., 2003. Long-horizon regressions: Theoretical results and applications. Journal of Financial Economics 68, 201-232.

Wachter, J., Yogo, M., 2010. Why do household portfolio shares rise in wealth? Review of Financial Studies 23, 3929-3965.

Wen, Y., 2002. The business cycle effect of Christmas. Journal of Monetary Economics 49, 1289-1314. 
Table 1. Summary statistics of quarterly growth rates of seasonally adjusted real macroeconomic variables.

\begin{tabular}{|c|c|c|c|c|}
\hline & $G^{1}$ & $G^{2}$ & $G^{3}$ & $G^{4}$ \\
\hline & \multicolumn{4}{|c|}{ Industrial production } \\
\hline Mean & $0.77 \%$ & $0.73 \%$ & $0.71 \%$ & $0.81 \%$ \\
\hline $\mathrm{SD}$ & $2.37 \%$ & $2.01 \%$ & $1.75 \%$ & $2.14 \%$ \\
\hline \multirow[t]{2}{*}{ AR1 } & -0.13 & -0.20 & -0.28 & -0.28 \\
\hline & \multicolumn{4}{|c|}{ GDP } \\
\hline Mean & $0.86 \%$ & $0.88 \%$ & $0.83 \%$ & $0.67 \%$ \\
\hline $\mathrm{SD}$ & $1.22 \%$ & $0.94 \%$ & $0.81 \%$ & $1.01 \%$ \\
\hline \multirow[t]{2}{*}{ AR1 } & -0.13 & 0.05 & 0.09 & -0.31 \\
\hline & \multicolumn{4}{|c|}{ Consumption } \\
\hline Mean & $0.51 \%$ & $0.54 \%$ & $0.46 \%$ & $0.50 \%$ \\
\hline $\mathrm{SD}$ & $0.50 \%$ & $0.49 \%$ & $0.49 \%$ & $0.53 \%$ \\
\hline AR1 & 0.02 & -0.05 & 0.21 & 0.05 \\
\hline \multicolumn{5}{|c|}{ Correlation matrix } \\
\hline & IP & GDP & $\mathrm{C}$ & \\
\hline IP & 1.00 & 0.87 & 0.54 & \\
\hline GDP & & 1.00 & 0.50 & \\
\hline $\mathrm{C}$ & & & 1.00 & \\
\hline
\end{tabular}

The table reports averages (Mean), standard deviations (SD), and first-order autoregressive coefficients (AR1) of quarterly real GDP growth rates (GDP), real per capita consumption growth rates (C), and industrial production growth rates (IP). The lower part of the table shows the correlations between the fourth-quarter $\left(G^{4}\right)$ growth rates of the different macroeconomic variables. The sample period is 1948-2009. 
Table 2. Predictive regressions of one-year-ahead excess stock returns on growth rates of real macroeconomic variables.

\begin{tabular}{|c|c|c|c|c|c|c|}
\hline & \multicolumn{4}{|c|}{ Value-weighted } & \multirow{2}{*}{\multicolumn{2}{|c|}{$\begin{array}{l}\text { Equal-weighted } \\
\qquad G^{4}\end{array}$}} \\
\hline & $G^{1}$ & $G^{2}$ & $G^{3}$ & $G^{4}$ & & \\
\hline \multicolumn{7}{|l|}{ Industrial production } \\
\hline$\beta$ & -1.22 & -1.02 & 0.72 & -3.78 & & -6.16 \\
\hline$t$-value & -1.55 & -0.91 & 0.63 & -5.74 & & -6.16 \\
\hline $\bar{R}^{2}$ & $0.79 \%$ & $-0.43 \%$ & $-1.24 \%$ & $17.93 \%$ & & $22.42 \%$ \\
\hline \multicolumn{7}{|l|}{$\underline{\text { GDP }}$} \\
\hline$\beta$ & -2.20 & -1.95 & 2.66 & -7.48 & & -11.78 \\
\hline$t$-value & -1.08 & -0.97 & 0.86 & -4.95 & & -4.96 \\
\hline $\bar{R}^{2}$ & $0.53 \%$ & $-0.66 \%$ & $-0.37 \%$ & $15.40 \%$ & & $17.95 \%$ \\
\hline \multicolumn{7}{|l|}{ Consumption } \\
\hline$\beta$ & 0.84 & -4.26 & -3.28 & -14.61 & & -21.98 \\
\hline$t$-value & 0.20 & -1.13 & -0.87 & -4.88 & & -5.25 \\
\hline $\bar{R}^{2}$ & $-1.64 \%$ & $-0.40 \%$ & $-0.99 \%$ & $16.05 \%$ & & $16.93 \%$ \\
\hline Benchmark variables & & $D P$ & $\widehat{c a y}$ & & $\overline{D P}$ & $\widehat{c a y}$ \\
\hline$\beta$ & & 4.96 & 3.87 & & 5.59 & 4.15 \\
\hline$t$-value & & 3.07 & 3.65 & & 2.63 & 2.50 \\
\hline $\bar{R}^{2}$ & & $10.82 \%$ & $11.78 \%$ & & $5.66 \%$ & $5.49 \%$ \\
\hline
\end{tabular}

For $G^{1}$, the one-year-ahead excess stock return is measured from the beginning of the second quarter to the end of the first quarter next year. For $G^{2}$, the one-year-ahead excess stock return is measured from the beginning of the third quarter to the end of the second quarter next year. For $G^{3}$, the one-year-ahead excess stock return is measured from the beginning of the fourth quarter to the end of the third quarter next year. For $G^{4}$ and the benchmark variables, the one-year-ahead excess stock return is measured over the calendar year. For each regression, the table reports the slope estimate, the Newey-West corrected $t$-value, and the adjusted $R^{2}$-statistic. The sample period is 1948-2009. 
Table 3. Predictive regressions of one-year-ahead excess stock returns on growth rates of real macroeconomic variables. Returns moved forward one quarter.

\begin{tabular}{|c|c|c|c|c|c|c|}
\hline & \multicolumn{4}{|c|}{ Value-weighted } & \multirow{2}{*}{\multicolumn{2}{|c|}{$\begin{array}{l}\text { Equal-weighted } \\
\qquad G^{4}\end{array}$}} \\
\hline & $G^{1}$ & $G^{2}$ & $G^{3}$ & $G^{4}$ & & \\
\hline \multicolumn{7}{|l|}{ Industrial production } \\
\hline $\bar{\beta}$ & -1.77 & -0.49 & -0.04 & -3.59 & & -5.97 \\
\hline$t$-value & -1.80 & -0.41 & -0.04 & -3.87 & & -4.63 \\
\hline $\bar{R}^{2}$ & $3.31 \%$ & $-1.43 \%$ & $-1.69 \%$ & $15.67 \%$ & & $22.28 \%$ \\
\hline \multicolumn{7}{|l|}{$\underline{\mathrm{GDP}}$} \\
\hline$\beta$ & -3.80 & -3.11 & 0.10 & -7.02 & & -11.82 \\
\hline$t$-value & -1.64 & -1.02 & 0.04 & -3.29 & & -3.83 \\
\hline $\bar{R}^{2}$ & $4.69 \%$ & $0.65 \%$ & $-1.69 \%$ & $13.05 \%$ & & $19.22 \%$ \\
\hline \multicolumn{7}{|l|}{ Consumption } \\
\hline$\beta$ & -1.77 & 1.99 & -9.63 & -13.39 & & -19.75 \\
\hline$t$-value & -0.43 & 0.45 & -3.01 & -3.93 & & -3.95 \\
\hline $\bar{R}^{2}$ & $-1.46 \%$ & $-1.44 \%$ & $4.78 \%$ & $12.92 \%$ & & $14.20 \%$ \\
\hline Benchmark variables & & $D P$ & $\widehat{c a y}$ & & $D P$ & $\widehat{c a y}$ \\
\hline$\beta$ & & 4.67 & 4.18 & & 4.82 & 3.88 \\
\hline$t$-value & & 2.89 & 4.36 & & 2.29 & 2.84 \\
\hline $\bar{R}^{2}$ & & $9.18 \%$ & $13.72 \%$ & & $4.09 \%$ & $4.94 \%$ \\
\hline
\end{tabular}

The table is as Table 2, except from the fact that returns have been moved forward one quarter, i.e., for $G^{4}$ and the benchmark variables, the one-year-ahead excess stock return is measured from the beginning of the second quarter to the end of the first quarter next year, for $G^{3}$, the one-year-ahead excess stock return is measured over the calendar year, for $G^{2}$, the one-yearahead excess stock return is measured from the beginning of the fourth quarter to the end of the third quarter next year, and for $G^{1}$, the one-year-ahead excess stock return is measured from the beginning of the third quarter to the end of the second quarter next year. For each regression, the table reports the slope estimate, the Newey-West corrected $t$-value, and the adjusted $R^{2}$-statistic. The sample period is 1948-2009. 
Table 4. Predictive regressions of cumulative long-horizon excess stock returns on quarterly growth rates of industrial production.

\begin{tabular}{|c|c|c|c|c|c|c|c|}
\hline & & $\mathrm{t} \rightarrow \mathrm{t}+1$ & $\mathrm{t} \rightarrow \mathrm{t}+2$ & $\mathrm{t} \rightarrow \mathrm{t}+3$ & $\mathrm{t} \rightarrow \mathrm{t}+4$ & $\mathrm{t} \rightarrow \mathrm{t}+8$ & $\mathrm{t} \rightarrow \mathrm{t}+12$ \\
\hline & & \multicolumn{6}{|c|}{ Value-weighted returns } \\
\hline \multirow[t]{3}{*}{$G^{I P, 4}$} & $\beta$ & -0.74 & -1.79 & -2.68 & -3.78 & -4.24 & -3.55 \\
\hline & $t$-value & -1.46 & -2.40 & -4.69 & -5.74 & -2.42 & -1.80 \\
\hline & $\bar{R}^{2}$ & $2.47 \%$ & $8.40 \%$ & $11.62 \%$ & $17.93 \%$ & $8.55 \%$ & $3.14 \%$ \\
\hline \multirow[t]{3}{*}{$G^{I P, 3}$} & $\beta$ & 0.45 & 0.63 & -0.37 & 0.72 & 0.47 & 1.73 \\
\hline & $t$-value & 0.67 & 0.63 & -0.30 & 0.63 & 0.32 & 1.46 \\
\hline & $\bar{R}^{2}$ & $-0.78 \%$ & $-0.98 \%$ & $-1.54 \%$ & $-1.24 \%$ & $-1.65 \%$ & $-1.02 \%$ \\
\hline \multirow[t]{3}{*}{$G^{I P, 2}$} & $\beta$ & 0.35 & -0.15 & -0.47 & -1.02 & 0.53 & -1.73 \\
\hline & $t$-value & 0.74 & -0.18 & -0.45 & -0.91 & 0.42 & -1.30 \\
\hline & $\bar{R}^{2}$ & $-1.06 \%$ & $-1.64 \%$ & $-1.32 \%$ & $-0.43 \%$ & $-1.57 \%$ & $-0.78 \%$ \\
\hline \multirow[t]{4}{*}{$G^{I P, 1}$} & $\beta$ & -0.14 & -0.11 & -0.78 & -1.22 & -0.21 & -0.84 \\
\hline & $t$-value & -0.33 & -0.18 & -1.11 & -1.55 & -0.16 & -0.65 \\
\hline & $\bar{R}^{2}$ & $-1.52 \%$ & $-1.66 \%$ & $-0.28 \%$ & $0.80 \%$ & $-1.70 \%$ & $-1.53 \%$ \\
\hline & & \multicolumn{6}{|c|}{ Equal-weighted returns } \\
\hline \multirow[t]{3}{*}{$G^{I P, 4}$} & $\beta$ & -1.40 & -3.29 & -4.64 & -6.16 & -7.11 & -6.57 \\
\hline & $t$-value & -1.82 & -2.83 & -4.76 & -6.16 & -2.78 & -1.92 \\
\hline & $\bar{R}^{2}$ & $5.29 \%$ & $14.10 \%$ & $18.29 \%$ & $22.43 \%$ & $11.39 \%$ & $5.57 \%$ \\
\hline
\end{tabular}

$G^{I P, i}$ is the growth rate of industrial production during quarter $i=1,2,3,4$. " $\mathrm{t} \rightarrow \mathrm{t}+1$ " indicates excess returns during the following quarter, i.e., for $G^{I P, 4}$, " $\mathrm{t} \rightarrow \mathrm{t}+1$ " indicates predictions of returns during the first quarter of the year, for $G^{I P, 3}$, " $\mathrm{t} \rightarrow \mathrm{t}+1$ " indicates predictions of returns during the fourth quarter of the year, etc. " $\mathrm{t} \rightarrow \mathrm{t}+2$ " indicates cumulative excess returns during the following two quarters, i.e., for $G^{I P, 4}$, " $\mathrm{t} \rightarrow \mathrm{t}+2$ " indicates predictions of cumulative returns during the first two quarters of the year, for $G^{I P, 3}$, " $\mathrm{t} \rightarrow \mathrm{t}+2$ " indicates predictions of cumulative returns during the fourth quarter of the year and the first quarter next year, etc. For each regression, the table reports the slope estimate, the Newey-West corrected $t$-value, and the adjusted $R^{2}$-statistic. The sample period is $1948-2009$. 
Table 5. Predictive regressions of one-year-ahead excess stock returns on inflation.

\begin{tabular}{crrrr}
\hline & $I N F^{1}$ & $I N F^{2}$ & $I N F^{3}$ & $I N F^{4}$ \\
\hline \multicolumn{5}{c}{ GDP price deflator } \\
$\beta$ & -3.14 & -6.67 & -3.15 & -4.27 \\
$t$-value & -1.27 & $-\mathbf{2 . 2 6}$ & -0.89 & -1.33 \\
$\bar{R}^{2}$ & $-0.15 \%$ & $3.41 \%$ & $-0.57 \%$ & $0.71 \%$ \\
\multicolumn{5}{c}{ CPI } \\
$\beta$ & -2.62 & -5.61 & -2.82 & -3.87 \\
$t$-value & -1.27 & $-\mathbf{2 . 0 9}$ & -1.13 & -1.70 \\
$\bar{R}^{2}$ & $0.19 \%$ & $3.83 \%$ & $-0.44 \%$ & $1.84 \%$ \\
& & & & \\
\hline
\end{tabular}

$I N F^{i}$ refers to the inflation rate during quarter $i=1,2,3$, and 4 . In the upper panel, inflation is computed based on the GDP price deflator from the Bureau of Economic Analysis. In the lower panel, inflation is computed based on the CPI (all items) from the Bureau of Labor Statistics. Both are seasonally adjusted. The timing is such that for $I N F^{1}$, the one-year-ahead excess stock return is measured from the beginning of the second quarter to the end of the first quarter next year. For $G^{2}$, the one-year-ahead excess stock return is measured from the beginning of the third quarter to the end of the second quarter next year, and so on for the other quarters. For each regression, the table reports the slope estimate, the Newey-West corrected $t$-value, and the adjusted $R^{2}$-statistic. The sample period is 1948-2009. 
Table 6. Predictive regressions of one-year-ahead excess stock returns on annual growth rates of real macroeconomic variables.

\begin{tabular}{ccccc}
\hline & & & & \\
& 1Q1Q & $2 \mathrm{Q} 2 \mathrm{Q}$ & $3 \mathrm{Q} 3 \mathrm{Q}$ & $4 \mathrm{Q} 4 \mathrm{Q}$ \\
\hline $\begin{array}{c}\text { Industrial production } \\
\text { t-value }\end{array}$ & -0.47 & -0.44 & -0.43 & -0.81 \\
$\bar{R}^{2}$ & -1.33 & -1.18 & -0.96 & -1.73 \\
& $0.58 \%$ & $0.44 \%$ & $-0.13 \%$ & $4.36 \%$ \\
$\frac{\text { GDP }}{\beta}$ & & & & \\
$t$-value & -1.16 & -1.21 & -0.96 & -1.72 \\
$\bar{R}^{2}$ & -1.77 & -1.46 & -1.04 & -1.88 \\
& $1.50 \%$ & $1.67 \%$ & $-0.00 \%$ & $4.55 \%$ \\
$\frac{}{\text { Consumption }}$ & & & & \\
\hline$\beta$ & -2.07 & -3.46 & -2.54 & -4.43 \\
$t$-value & -1.35 & -1.83 & -1.42 & $-\mathbf{3 . 2 5}$ \\
$\bar{R}^{2}$ & $0.78 \%$ & $4.27 \%$ & $1.36 \%$ & $9.50 \%$ \\
& & & & \\
\hline
\end{tabular}

1Q1Q is the annual growth rate from the first quarter last year to the first quarter this year, $2 \mathrm{Q} 2 \mathrm{Q}$ is the annual growth rate from the second quarter last year to the second quarter this year, etc. The timing of returns is as in Table 2. For each regression, the table reports the slope estimate, the Newey-West corrected $t$-value, and the adjusted $R^{2}$-statistic. The sample period is 1948-2009. 
Table 7. Predictive regressions of one-year-ahead excess stock returns on quarterly (Q3Q4) and annual (Q4Q4) growth in consumption.

\begin{tabular}{ccccccc}
\hline & Q3Q4 & Q4Q4 & Q3Q4 $^{\perp}$ & Q4Q4 & Q3Q4 & Q4Q4 \\
\hline$\beta$ & -12.40 & -1.26 & -12.40 & -4.36 & -14.65 & -1.26 \\
$t$-value & $-\mathbf{2 . 7 1}$ & -0.66 & $-\mathbf{2 . 7 1}$ & $-\mathbf{3 . 3 8}$ & $-\mathbf{4 . 8 7}$ & -0.66 \\
$\bar{R}^{2}$ & $15.11 \%$ & \multicolumn{2}{c}{$15.11 \%$} & \multicolumn{2}{c}{$15.11 \%$} \\
& & & & & \\
\hline
\end{tabular}

The table shows results from regressing one-year-ahead excess returns on two measures of fourthquarter growth in consumption, namely the consumption growth from the third to the fourth quarter (Q3Q4) and the year-over-year fourth-quarter growth rate (Q4Q4). In the left panel, we show results from a joint regression using both Q3Q4 and Q4Q4 consumption growth. In the middle panel, we orthogonalize the Q3Q4 consumption growth rate with respect to the Q4Q4 consumption growth rate and use both in a joint regression. In the right panel, we orthogonalize the Q4Q4 consumption growth rate with respect to the Q3Q4 consumption growth rate and use both in a joint regression. For each regression, the table reports the slope estimate, the Newey-West corrected $t$-value, and the adjusted $R^{2}$-statistic. The sample period is 1948-2009. 
Table 8. Predictive regressions of one-year-ahead excess returns on monthly growth rates in industrial production.

\begin{tabular}{lrrrrrr}
\hline & \multicolumn{3}{c}{ Value-weighted } & \multicolumn{3}{c}{ Equal-weighted } \\
& $\beta$ & $t$-value & \multicolumn{1}{c}{$\bar{R}^{2}$} & $\beta$ & $t$-value & $\bar{R}^{2}$ \\
\hline & & & & & & \\
December & -4.59 & $\mathbf{- 3 . 3 1}$ & $9.10 \%$ & -8.24 & $-\mathbf{3 . 5 8}$ & $14.68 \%$ \\
November & -4.16 & $\mathbf{- 2 . 6 3}$ & $5.87 \%$ & -5.80 & $\mathbf{- 2 . 5 0}$ & $5.75 \%$ \\
October & -3.50 & $\mathbf{- 2 . 0 5}$ & $2.05 \%$ & -5.15 & $\mathbf{- 2 . 2 3}$ & $2.38 \%$ \\
September & -2.70 & -1.26 & $0.50 \%$ & -4.36 & $-\mathbf{2 . 1 5}$ & $1.68 \%$ \\
August & 0.29 & 0.18 & $-1.65 \%$ & -1.13 & -0.62 & $-1.28 \%$ \\
July & 2.68 & 1.31 & $0.20 \%$ & 2.33 & 0.83 & $-0.80 \%$ \\
June & -0.69 & -0.19 & $-1.62 \%$ & -2.14 & -0.43 & $-1.25 \%$ \\
May & -2.06 & -0.75 & $-0.75 \%$ & -5.97 & -1.47 & $2.56 \%$ \\
April & -2.21 & -0.86 & $-0.20 \%$ & -4.90 & -1.31 & $2.17 \%$ \\
March & -1.93 & -0.69 & $-0.83 \%$ & -4.42 & -1.07 & $0.70 \%$ \\
February & -2.56 & -0.91 & $0.00 \%$ & -6.66 & -1.89 & $4.08 \%$ \\
January & -0.06 & -0.04 & $-1.69 \%$ & -2.17 & -1.01 & $-0.79 \%$ \\
\hline
\end{tabular}

When using December growth rates to predict, the one-year-ahead excess return is measured from the beginning of January to the end of December; when using November growth rates to predict, the one-year-ahead excess return is measured from the beginning of December to the end of November next year; etc. For each regression, the table reports the slope estimate, the Newey-West corrected $t$-value, and the adjusted $R^{2}$-statistic. The sample period is 1948-2009. 
Table 9. Out-of-sample regressions of one-year-ahead excess stock returns on the fourth-quarter growth rate of economic variables.

\begin{tabular}{|c|c|c|c|c|c|c|c|c|}
\hline & \multicolumn{3}{|c|}{ Value-weighted } & \multicolumn{5}{|c|}{ Equal-weighted } \\
\hline & OOS $R^{2}$ & $E N C$ & $M S E-F$ & $t(N W)$ & OOS $R^{2}$ & $E N C$ & $M S E-F$ & $t(N W)$ \\
\hline \multicolumn{9}{|c|}{ Q4 variables. Now available data } \\
\hline Indu. prod. & $10.87 \%$ & 3.75 & 4.27 & 1.60 & $19.59 \%$ & 6.05 & 8.52 & 2.06 \\
\hline GDP & $12.57 \%$ & 3.65 & 5.03 & 1.79 & $19.75 \%$ & 5.66 & 8.61 & 2.24 \\
\hline Consump. & $9.75 \%$ & 3.35 & 3.78 & 2.16 & $12.49 \%$ & 3.77 & 5.00 & 2.32 \\
\hline \multicolumn{9}{|c|}{ Q4 variables. Vintage data } \\
\hline Indu. prod. & $12.33 \%$ & 4.24 & 4.92 & 1.58 & $20.74 \%$ & 6.56 & 9.16 & 2.16 \\
\hline Consump. & $9.38 \%$ & 2.83 & 3.62 & 1.73 & $9.86 \%$ & 2.90 & 3.83 & 1.33 \\
\hline \multicolumn{9}{|c|}{ Benchmark variables } \\
\hline$D P$ & $-4.18 \%$ & 1.56 & -1.40 & 0.79 & $-2.76 \%$ & 1.15 & -0.94 & 0.93 \\
\hline$\widehat{c a y}$ & $2.66 \%$ & 3.53 & 0.96 & 2.37 & $-2.25 \%$ & 0.89 & -0.77 & 1.11 \\
\hline
\end{tabular}

$E N C-N E W$ is the forecast encompassing test of Clark and McCracken (2001). MSE-F is the equal forecast accuracy test of McCracken (2007). $t(N W)$ is the adjusted test in Clark and West (2007). Asymptotic critical values at the 5\% significance level are 1.85 for the $E N C$-NEW test, 1.62 for the $M S E-F$ test, and 1.65 for the $t(N W)$ test. OOS $R^{2}$ is the unconstrained Campbell and Thompson (2008) out-of-sample $R^{2}$-statistic. The one-year-ahead excess stock return is measured from the beginning of the second quarter to the end of the first quarter next year. The out-of-sample window runs from 1975 to 2009. 
Table 10. One-year-ahead excess returns regressed on changes in macro variables.

\begin{tabular}{|c|c|c|c|c|}
\hline & $G^{1}$ & $G^{2}$ & $G^{3}$ & $G^{4}$ \\
\hline & \multicolumn{4}{|c|}{ Change in output gap, CBO measure } \\
\hline$\beta$ & -0.02 & -0.01 & 0.07 & -0.10 \\
\hline$t$-value & -0.42 & -0.36 & 1.39 & -4.11 \\
\hline \multirow[t]{2}{*}{$\bar{R}^{2}$} & $-1.16 \%$ & $-1.61 \%$ & $1.38 \%$ & $9.24 \%$ \\
\hline & \multicolumn{4}{|c|}{ Change in investment-capital ratio } \\
\hline$\beta$ & -33.8 & -15.6 & -26.2 & -53.5 \\
\hline$t$-value & -1.85 & -0.67 & -0.79 & -2.13 \\
\hline \multirow[t]{2}{*}{$\bar{R}^{2}$} & $1.88 \%$ & $-0.95 \%$ & $-0.27 \%$ & $5.17 \%$ \\
\hline & \multicolumn{4}{|c|}{ Change in housing-collateral ratio } \\
\hline$\beta$ & 5.31 & -2.12 & 1.91 & 9.51 \\
\hline$t$-value & 1.46 & -0.72 & 0.47 & 2.75 \\
\hline \multirow[t]{2}{*}{$\bar{R}^{2}$} & $2.79 \%$ & $-1.16 \%$ & $-1.53 \%$ & $14.28 \%$ \\
\hline & \multicolumn{4}{|c|}{ Employment growth (nonfarm) } \\
\hline$\beta$ & -6.98 & -5.15 & -2.73 & -11.05 \\
\hline$t$-value & -3.07 & -1.36 & -0.66 & -3.80 \\
\hline \multirow[t]{2}{*}{$\bar{R}^{2}$} & $6.59 \%$ & $2.09 \%$ & $-0.95 \%$ & $14.83 \%$ \\
\hline & \multicolumn{4}{|c|}{ Labor income growth } \\
\hline$\beta$ & -3.88 & 1.39 & -5.94 & -8.43 \\
\hline$t$-value & -1.53 & 0.81 & -1.72 & -3.35 \\
\hline \multirow[t]{2}{*}{$\bar{R}^{2}$} & $2.56 \%$ & $-1.31 \%$ & $5.09 \%$ & $11.21 \%$ \\
\hline & \multicolumn{4}{|c|}{ Change in capacity utilization } \\
\hline$\beta$ & -0.03 & -0.03 & 0.02 & -0.05 \\
\hline$t$-value & -3.30 & -1.16 & 0.44 & -2.90 \\
\hline \multirow[t]{2}{*}{$\bar{R}^{2}$} & $1.97 \%$ & -0.28 & $-2.01 \%$ & $8.81 \%$ \\
\hline & \multicolumn{4}{|c|}{ Nonresidential investment growth } \\
\hline$\beta$ & -1.33 & -0.68 & -1.05 & -2.24 \\
\hline$t$-value & -2.28 & -0.84 & -0.98 & -3.17 \\
\hline $\bar{R}^{2}$ & $2.93 \%$ & $-0.61 \%$ & $0.39 \%$ & $8.31 \%$ \\
\hline
\end{tabular}

$G^{i}$ refers to the growth rate during quarter $i=1,2,3$, and 4 . The timing is such that for $G^{1}$, the one-year-ahead excess stock return is measured from the beginning of the second quarter to the end of the first quarter next year, and so on for the other quarters (see also notes to Table 2). The sample period is $1948-2009$ 
Table 11. International evidence on excess return predictability by global fourth-quarter growth rates of industrial production.

\begin{tabular}{|c|c|c|c|c|c|c|c|c|c|}
\hline \multicolumn{6}{|c|}{ G7 growth rates } & \multicolumn{4}{|c|}{ Equal-weighted growth rates } \\
\hline & $G^{1}$ & $G^{2}$ & $G^{3}$ & $G^{4}$ & & $G^{1}$ & $G^{2}$ & $G^{3}$ & $G^{4}$ \\
\hline \multicolumn{6}{|c|}{ World } & \multicolumn{4}{|c|}{ World } \\
\hline$\beta$ & -0.87 & -1.63 & -0.77 & -3.29 & $\beta$ & -1.60 & -1.31 & -3.31 & -3.78 \\
\hline$t$-value & -0.91 & -0.74 & -0.26 & -3.20 & $t$-value & -0.75 & -0.79 & -0.93 & -3.90 \\
\hline \multirow[t]{2}{*}{$\bar{R}^{2}$} & $-2.34 \%$ & $-1.59 \%$ & $-2.54 \%$ & $6.63 \%$ & $\bar{R}^{2}$ & $-2.09 \%$ & $-2.01 \%$ & $-0.54 \%$ & $8.61 \%$ \\
\hline & \multicolumn{4}{|c|}{ World excl. US } & & \multicolumn{4}{|c|}{ World excl. US } \\
\hline$\beta$ & 1.18 & -0.44 & -0.74 & -3.44 & $\beta$ & -0.84 & -0.68 & -3.12 & -4.54 \\
\hline$t$-value & 1.06 & -0.20 & -0.26 & -3.86 & $t$-value & -0.32 & -0.33 & -0.95 & -5.43 \\
\hline \multirow[t]{2}{*}{$\bar{R}^{2}$} & $-2.29 \%$ & $-2.65 \%$ & $-2.60 \%$ & $4.38 \%$ & $\bar{R}^{2}$ & $-2.60 \%$ & $-2.58 \%$ & $-1.31 \%$ & $8.61 \%$ \\
\hline & \multicolumn{5}{|c|}{ Europe, Australia and the Far East } & \multicolumn{4}{|c|}{ Europe, Australia and the Far East } \\
\hline$\beta$ & 0.99 & -0.54 & -1.02 & -3.55 & $\beta$ & -0.36 & -0.92 & -3.71 & -4.75 \\
\hline$t$-value & 0.88 & -0.26 & -0.37 & -3.37 & $t$-value & -0.13 & -0.47 & -1.11 & -5.02 \\
\hline \multirow[t]{2}{*}{$\bar{R}^{2}$} & $-2.42 \%$ & $-2.62 \%$ & $-2.51 \%$ & $4.40 \%$ & $\bar{R}^{2}$ & $-2.68 \%$ & $-2.48 \%$ & $-0.80 \%$ & $8.97 \%$ \\
\hline & \multicolumn{4}{|c|}{ Europe } & & \multicolumn{4}{|c|}{ Europe } \\
\hline$\beta$ & 0.49 & 1.89 & 1.04 & -3.83 & $\beta$ & 0.22 & 1.78 & -1.50 & -4.51 \\
\hline$t$-value & 0.41 & 0.68 & 0.30 & -3.29 & $t$-value & 0.07 & 0.70 & -0.42 & -4.18 \\
\hline $\bar{R}^{2}$ & $-2.63 \%$ & $-1.75 \%$ & $-2.45 \%$ & $5.98 \%$ & $\bar{R}^{2}$ & $-2.70 \%$ & $-1.88 \%$ & $-2.31 \%$ & $8.33 \%$ \\
\hline
\end{tabular}

We use excess returns in US dollars from the MSCI World, MSCI World excl. US, MSCI EAFE, and MSCI Europe index. For $G^{1}$, the one-year-ahead excess stock return is measured from the beginning of the second quarter to the end of the first quarter next year. For $G^{2}$, the oneyear-ahead excess stock return is measured from the beginning of the third quarter to the end of the second quarter next year. For $G^{3}$, the one-year-ahead excess stock return is measured from the beginning of the fourth quarter to the end of the third quarter next year. For $G^{4}$, the one-year-ahead excess stock return is measured over the calendar year. In the left-hand panel, we use G7 industrial production to compute growth rates. In the right-hand panel, we compute growth rates based on an equal-weighted average of industrial production in Australia, Belgium, France, Germany, Japan, Italy, Netherlands, Sweden, Switzerland, UK, and US is used. For each regression, the table reports the slope estimate, the Newey-West corrected $t$-value, and the adjusted $R^{2}$-statistic. The sample period is 1948-2009. 
Table 12. Using the surplus consumption ratio to capture movements in one-year-ahead excess returns.

\begin{tabular}{|c|c|c|c|c|c|c|c|c|}
\hline & \multicolumn{4}{|c|}{ Value-weighted returns } & \multicolumn{4}{|c|}{ Equal-weighted returns } \\
\hline & $S^{1}$ & $S^{2}$ & $S^{3}$ & $S^{4}$ & $S^{1}$ & $S^{2}$ & $S^{3}$ & $S^{4}$ \\
\hline \multicolumn{9}{|c|}{ Panel A: Levels of the surplus consumption ratio } \\
\hline$\beta$ & -3.86 & -4.07 & -3.74 & -4.98 & -3.27 & -3.75 & -3.51 & -5.19 \\
\hline$t$-value & -2.65 & -2.48 & -2.27 & -3.82 & -1.67 & -1.59 & -1.51 & -2.43 \\
\hline $\bar{R}^{2}$ & $8.75 \%$ & $8.85 \%$ & $6.46 \%$ & $15.16 \%$ & $2.27 \%$ & $3.47 \%$ & $2.53 \%$ & $6.77 \%$ \\
\hline \multicolumn{9}{|c|}{ Panel B: Changes in the surplus consumption ratio } \\
\hline$\beta$ & 0.13 & 0.00 & 0.02 & -0.45 & -0.00 & -0.13 & -0.13 & -0.71 \\
\hline$t$-value & 1.29 & 0.04 & 0.16 & -3.01 & -0.01 & -0.64 & -1.03 & -3.00 \\
\hline $\bar{R}^{2}$ & $-0.35 \%$ & $-1.67 \%$ & $-1.67 \%$ & $7.82 \%$ & $-1.69 \%$ & $-0.98 \%$ & $-1.16 \%$ & $9.12 \%$ \\
\hline
\end{tabular}

One-year-ahead excess returns on the value-weighted portfolio and the equal-weighted portfolio regressed on the surplus consumption ratio (Panel A) and the change in the surplus consumption ratio (Panel B). $S^{i}$ refers to the surplus consumption ratio in quarter $i=1,2,3$, and 4 . The timing is such that for $S^{1}$, the one-year-ahead excess stock return is measured from the beginning of the second quarter to the end of the first quarter next year, and so on for the other quarters (see also notes to Table 2). The sample period is 1948-2009. 
Table 13. Growth in consumer confidence and expected returns.

\begin{tabular}{|c|c|c|c|c|c|c|c|c|}
\hline & \multicolumn{4}{|c|}{ Value-weighted returns } & \multicolumn{4}{|c|}{ Equal-weighted returns } \\
\hline & $G^{1}$ & $G^{2}$ & $G^{3}$ & $G^{4}$ & $G^{1}$ & $G^{2}$ & $G^{3}$ & $G^{4}$ \\
\hline & \multicolumn{8}{|c|}{ Conference board } \\
\hline$\beta$ & 0.90 & 0.12 & -0.49 & -0.35 & -0.19 & 0.04 & -0.82 & -0.96 \\
\hline$t$-value & 0.27 & 0.54 & -1.64 & -2.06 & -0.37 & 0.12 & -2.01 & -3.93 \\
\hline \multirow[t]{2}{*}{$\bar{R}^{2}$} & $-2.31 \%$ & $-1.75 \%$ & $1.86 \%$ & $2.69 \%$ & $-2.01 \%$ & $-2.50 \%$ & $4.28 \%$ & $15.62 \%$ \\
\hline & \multicolumn{8}{|c|}{ University of Michigan } \\
\hline$\beta$ & 0.44 & 0.31 & -0.62 & -0.65 & 0.20 & 0.30 & -0.89 & -1.38 \\
\hline$t$-value & 0.93 & 0.64 & -1.61 & -1.60 & 0.27 & 0.41 & -1.85 & -2.54 \\
\hline $\bar{R}^{2}$ & $-0.35 \%$ & $-1.03 \%$ & $0.53 \%$ & $2.00 \%$ & $-2.34 \%$ & $-1.80 \%$ & $1.01 \%$ & $6.85 \%$ \\
\hline
\end{tabular}

One-year-ahead excess returns on the value-weighted portfolio and the equal-weighted portfolio regressed on growth in consumer confidence. $G^{i}$ refers to the growth in the index in quarter $i=1,2,3$, and 4 . The timing is such that for $G^{1}$, the one-year-ahead excess stock return is measured from the beginning of the second quarter to the end of the first quarter next year, and so on for the other quarters (see also notes to Table 2). The sample period is 1948-2009. 
Fig. 1: The fourth-quarter growth rate of macroeconomic time series together with NBER recessions.

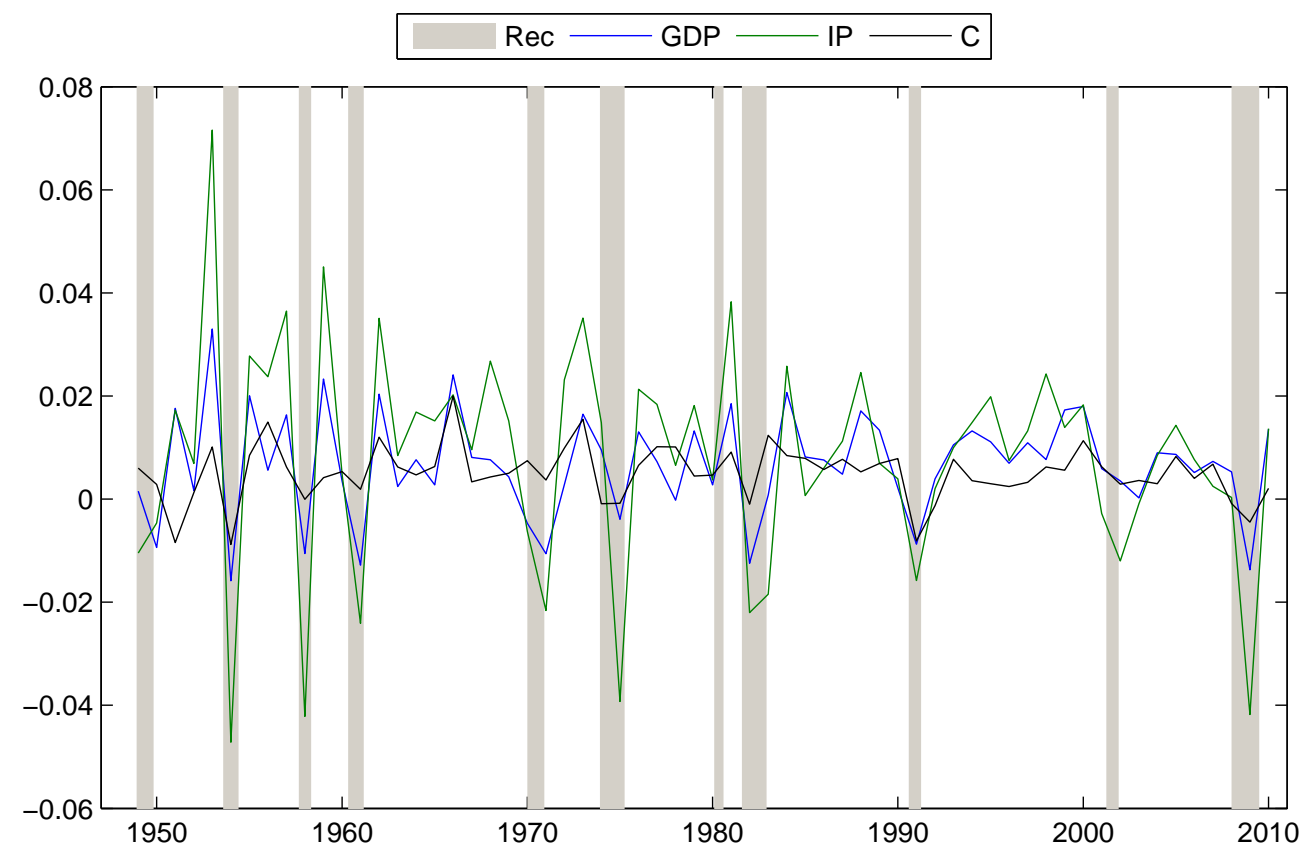


Fig. 2: Results (coefficients, $t$-statistics, and $R^{2} \mathrm{~s}$ ) from rolling regressions.
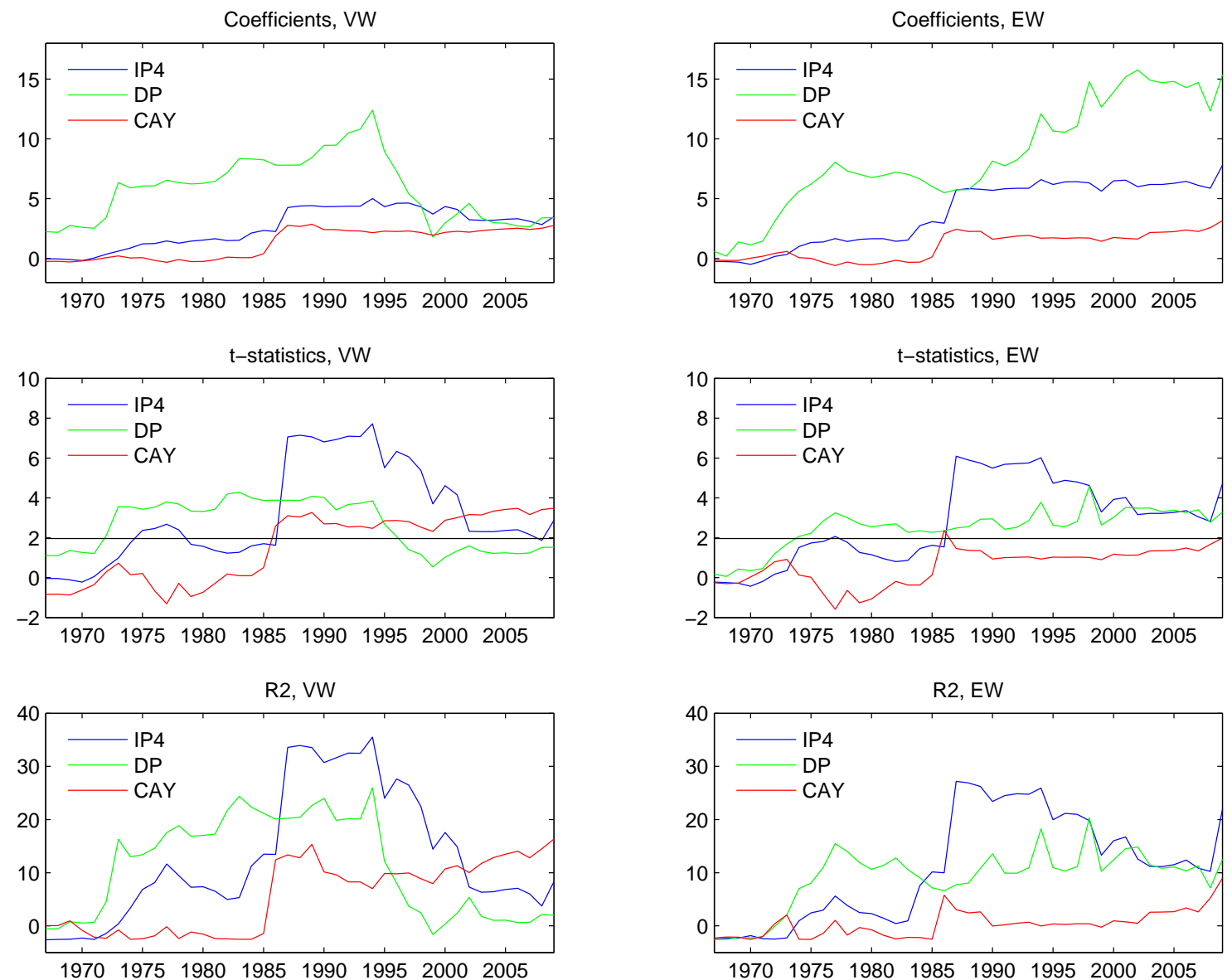

IP4 is the fourth-quarter growth rate in industrial production, $D P$ is the dividend-price ratio, and CAY is the $\widehat{c a y}$-ratio of Lettau and Ludvigson (2001). 40 years of data are used in each regression. Coefficients and $t$-values associated with $G^{I P, 4}$ have been multiplied with -1 . Sample period: $1927-2009$. 
Fig. 3: Net new cash flows to equity and money market mutual funds.

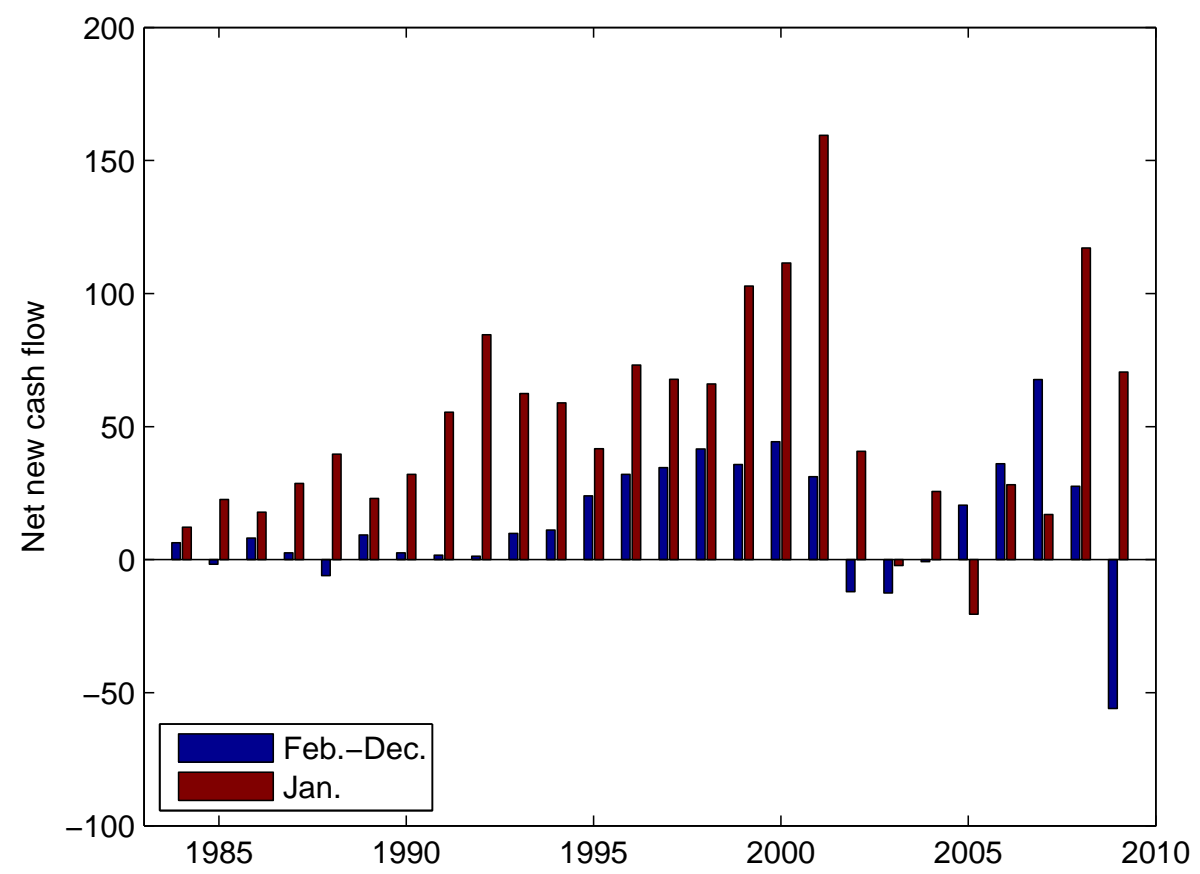

The figure plots the net new cash flows to equity and money market mutual funds in January and the average flow during the other months of the year. The net new cash flow is defined as new sales minus redemptions, plus net exchanges. The source is the Investment Company Institute. We adjust the flows for inflation using the CPI. The flows are presented in December 2009 prices (in billions). The sample period is 1984-2009. 
Internet appendix to

End-of-the-year economic growth and time-varying expected returns 


\section{Appendix A. Additional results.}

Table A1. Predictive regressions of one-year-ahead excess stock returns on inflation.

\begin{tabular}{|c|c|c|c|c|c|c|c|c|}
\hline & \multicolumn{4}{|c|}{ Quarter-to-quarter inflation } & \multicolumn{4}{|c|}{ Year-over-year inflation } \\
\hline & Q4Q1 & Q1Q2 & Q2Q3 & Q3Q4 & Q1Q1 & Q2Q2 & Q3Q3 & Q4Q4 \\
\hline & \multicolumn{8}{|c|}{ GDP price deflator inflation } \\
\hline$\beta$ & -3.14 & -6.67 & -3.15 & -4.27 & -0.91 & -1.11 & -1.22 & -0.90 \\
\hline$t$-value & -1.27 & -2.26 & -0.89 & -1.33 & -1.25 & -1.55 & -1.30 & -1.03 \\
\hline \multirow[t]{2}{*}{$\bar{R}^{2}$} & $-0.15 \%$ & $3.41 \%$ & $-0.57 \%$ & $0.71 \%$ & $-0.04 \%$ & $0.56 \%$ & $0.65 \%$ & $-0.36 \%$ \\
\hline & \multicolumn{8}{|c|}{ Headline CPI inflation } \\
\hline$\beta$ & -2.62 & -5.61 & -2.82 & -3.87 & -0.47 & -0.88 & -1.13 & -0.60 \\
\hline$t$-value & -1.27 & -2.09 & -1.13 & -1.70 & -0.81 & -1.54 & -1.67 & -0.95 \\
\hline \multirow[t]{2}{*}{$\bar{R}^{2}$} & $0.19 \%$ & $3.83 \%$ & $-0.44 \%$ & $1.84 \%$ & $-1.03 \%$ & $0.49 \%$ & $1.48 \%$ & $-0.76 \%$ \\
\hline & \multicolumn{8}{|c|}{ Headline PCE inflation } \\
\hline$\beta$ & -3.42 & -6.91 & -2.66 & -3.98 & -0.65 & -1.21 & -1.16 & -0.65 \\
\hline$t$-value & -1.37 & -2.31 & -0.81 & -1.43 & -0.96 & -1.89 & -1.30 & -0.84 \\
\hline \multirow[t]{2}{*}{$\bar{R}^{2}$} & $0.34 \%$ & $4.74 \%$ & $-0.88 \%$ & $0.60 \%$ & $-0.79 \%$ & $1.19 \%$ & $0.62 \%$ & $-0.91 \%$ \\
\hline & \multicolumn{8}{|c|}{ Core PCE inflation } \\
\hline$\beta$ & -0.10 & 0.14 & 0.98 & -1.03 & 0.32 & -0.07 & 0.18 & 0.18 \\
\hline$t$-value & -0.03 & 0.04 & 0.25 & -0.28 & 0.36 & -0.08 & 0.16 & 0.19 \\
\hline \multirow[t]{2}{*}{$\bar{R}^{2}$} & $-2.13 \%$ & $-2.13 \%$ & $-2.04 \%$ & $-2.02 \%$ & $-1.95 \%$ & $-2.12 \%$ & $-2.09 \%$ & $-2.08 \%$ \\
\hline & \multicolumn{8}{|c|}{ Core CPI inflation } \\
\hline$\beta$ & 0.47 & 1.15 & 1.75 & -0.44 & 0.53 & 0.49 & 0.24 & 0.33 \\
\hline$t$-value & 0.16 & 0.42 & 0.58 & -0.14 & 0.75 & 0.66 & 0.24 & 0.41 \\
\hline $\bar{R}^{2}$ & $-2.01 \%$ & $-1.86 \%$ & $-1.61 \%$ & $-2.01 \%$ & $-1.41 \%$ & $-1.51 \%$ & $-1.93 \%$ & $-1.79 \%$ \\
\hline
\end{tabular}

In the left panel, inflation is computed quarter-to-quarter and in the right panel year-over-year. For example, Q3Q4 is the inflation rate from the third quarter to the fourth quarter, whereas Q4Q4 is the annual inflation rate from the fourth quarter last year to the fourth quarter this year. We compute inflation using either the GDP price deflator, the consumer price index (CPI), or the personal consumption expenditures chain-type price index (PCE). We use both headline and core measures of inflation for the CPI and PCE. The core measures do not include energy and food prices, whereas the headline measures include all items in the price indexes. All measures are seasonally adjusted. The timing is such that for Q4Q1 and Q1Q1, the oneyear-ahead excess stock return is measured from the beginning of the second quarter to the end of the first quarter next year. For Q1Q2 and Q2Q2, the one-year-ahead excess stock return is 
measured from the beginning of the third quarter to the end of the second quarter next year, and so on for the other quarters. For each regression, the table reports the slope estimate, the Newey-West corrected $t$-value, and the adjusted $R^{2}$-statistic. The sample period is 1948-2009 for the headline measures and the GDP price deflator, 1958-2009 for core CPI inflation, and 1960-2009 for core PCE inflation. 
Table A2. Book-to-market and dividend-yield portfolios regressed on fourth-quarter industrial production growth.

\begin{tabular}{|c|c|c|c|c|c|c|c|c|c|c|c|c|}
\hline & & 1 & 2 & 3 & 4 & 5 & 6 & 7 & 8 & 9 & 10 & $10-1$ \\
\hline \multicolumn{13}{|c|}{ Book-to-market portfolios } \\
\hline$\beta$ & & -5.94 & -5.40 & -5.81 & -5.77 & -5.88 & -5.42 & -5.70 & -6.04 & -6.37 & -7.88 & -1.94 \\
\hline$t$-value & & -4.47 & -4.72 & -5.19 & -5.32 & -6.33 & -6.29 & -6.71 & -6.58 & -6.51 & -6.35 & -2.16 \\
\hline $\bar{R}^{2}$ & & $15.7 \%$ & $18.8 \%$ & $23.6 \%$ & $23.1 \%$ & $25.3 \%$ & $21.5 \%$ & $23.0 \%$ & $22.7 \%$ & $22.8 \%$ & $22.0 \%$ & $2.3 \%$ \\
\hline & 0 & 1 & 2 & 3 & 4 & 5 & 6 & 7 & 8 & 9 & 10 & $0-10$ \\
\hline \multicolumn{13}{|c|}{ Dividend-yield portfolios } \\
\hline$\beta$ & -8.45 & -5.32 & -4.86 & -4.58 & -4.65 & -4.60 & -4.76 & -4.65 & -4.88 & -4.62 & -5.42 & -3.03 \\
\hline$t$-value & -6.14 & -5.91 & -5.55 & -4.90 & -5.84 & -5.60 & -5.47 & -5.92 & -6.57 & -6.16 & -6.70 & -3.60 \\
\hline $\bar{R}^{2}$ & $19.8 \%$ & $18.5 \%$ & $19.8 \%$ & $18.1 \%$ & $19.8 \%$ & $20.1 \%$ & $21.3 \%$ & $21.0 \%$ & $22.8 \%$ & $21.9 \%$ & $25.4 \%$ & $4.9 \%$ \\
\hline
\end{tabular}

We regress one-year-ahead excess returns on the fourth-quarter growth rate in industrial production. In the upper panel, we use returns from ten decile portfolios formed on book-to-market. "1" refers to the porfolio with the lowest book-to-market ratio, whereas "10" refers to the portfolio with highest book-to-market ratio. In the lower panel, we use returns from ten decile portfolios formed on dividend yield. "1" refers to the portfolio with the lowest dividend yield and "10" refers to the portfolio with the highest dividend yield. "0" refers to a no-dividend paying portfolio. For each regression, the table reports the slope estimate, the Newey-West corrected $t$-value, and the adjusted $R^{2}$-statistic. The sample period is 1948-2009. 
Table A3. Predictive regressions of one-year-ahead excess returns from a two-year bond on growth rates of real macroeconomic variables.

\begin{tabular}{ccrcc}
\hline & $G^{1}$ & $G^{2}$ & \multicolumn{1}{c}{$G^{3}$} & $G^{4}$ \\
\hline \multicolumn{5}{c}{ Industrial production } \\
$\beta$ & -0.12 & 0.02 & -0.13 & -0.27 \\
$t$-value & -1.11 & 0.11 & -0.94 & $\mathbf{- 2 . 9 2}$ \\
$\bar{R}^{2}$ & $0.29 \%$ & $-1.82 \%$ & $-0.73 \%$ & $9.25 \%$ \\
& \multicolumn{5}{c}{ GDP } \\
\cline { 2 - 5 }$\beta$ & -0.29 & 0.09 & -0.26 & -0.45 \\
$t$-value & -1.18 & 0.25 & -0.90 & $-\mathbf{2 . 2 2}$ \\
$\bar{R}^{2}$ & $1.68 \%$ & $-1.65 \%$ & $-0.43 \%$ & $4.71 \%$ \\
& \multicolumn{5}{c}{ Consumption } \\
\cline { 2 - 5 }$\beta$ & -0.59 & 0.26 & -1.28 & -0.80 \\
$t$-value & -1.31 & 0.30 & $-\mathbf{2 . 4 5}$ & $-\mathbf{2 . 6 1}$ \\
$\bar{R}^{2}$ & $0.59 \%$ & $-1.46 \%$ & $7.95 \%$ & $4.05 \%$ \\
\multicolumn{5}{c}{}
\end{tabular}

We use the Fama-Bliss dataset to calculate excess bond returns. For $G^{1}$, the one-year-ahead excess bond return is measured from the beginning of the second quarter to the end of the first quarter next year. For $G^{2}$, the one-year-ahead excess bond return is measured from the beginning of the third quarter to the end of the second quarter next year. For $G^{3}$, the one-year-ahead excess bond return is measured from the beginning of the fourth quarter to the end of the third quarter next year. For $G^{4}$, the one-year-ahead excess bond return is measured over the calendar year. For each regression, the table reports the slope estimate, the Newey-West corrected $t$-value, and the adjusted $R^{2}$-statistic. The sample period is 1953-2009. Following Cochrane and Piazzesi (2005), among others, we subtract the 1-year yield when calculating excess bond returns. We also checked predictions of excess returns on bonds of different maturities: 2 years, 3 years, 4 years, and 5 years. We found that the Q4 economic growth rate is a significant predictor of bonds of different maturities, and that the growth rates of macroeconomic variables during other quarters of the year generally do not predict bond returns. 
Table A4. Predictive regressions of one-year-ahead excess stock returns on quarterly growth rates of industrial production, based on end-of-quarter series.

\begin{tabular}{crrrr}
\hline & \multicolumn{1}{c}{$G^{1}$} & \multicolumn{1}{c}{$G^{2}$} & \multicolumn{1}{c}{$G^{3}$} & \multicolumn{1}{c}{$G^{4}$} \\
\hline$\beta$ & -0.85 & -0.76 & -0.21 & -6.20 \\
$t$-value & -0.81 & -0.65 & -0.22 & $-\mathbf{6 . 3 3}$ \\
$\bar{R}^{2}$ & $-0.75 \%$ & $-0.95 \%$ & $-1.64 \%$ & $17.26 \%$ \\
& & & & \\
\hline
\end{tabular}

For $G^{1}$, the one-year-ahead excess stock return is measured from the beginning of the second quarter to the end of the first quarter next year. For $G^{2}$, the one-year-ahead excess stock return is measured from the beginning of the third quarter to the end of the second quarter next year. For $G^{3}$, the one-year-ahead excess stock return is measured from the beginning of the fourth quarter to the end of the third quarter next year. For $G^{4}$, the one-year-ahead excess stock return is measured over the calendar year. For each regression, the table reports the slope estimate, the Newey-West corrected $t$-value, and the adjusted $R^{2}$-statistic. The sample period is $1948-2009$. 


\section{Appendix B. Out-of-sample forecasting and tests.}

First, we estimate the unrestricted forecasting model, $R_{t+1}^{e}=\alpha+\beta X_{t}+\varepsilon_{t+1}$, where $R_{t+1}^{e}$ is the one-year-ahead excess return and $X_{t}$ is the forecasting variable, using annual data from 1948 to 1974 and make a forecast for 1975 . Then, we re-estimate the model using data from 1948 to 1975 and make a forecast for 1976. This procedure continues until the end of the sample in 2009, i.e., our out-of-sample period is 1975-2009. In a similar way, we generate out-of-sample forecasts using a restricted forecasting model with $\beta=0$. Let $\hat{\varepsilon}_{U}$ denote the vector of forecast errors using the unrestricted forecasting model, and let $\hat{\varepsilon}_{R}$ denote the vector forecast errors using the restricted forecasting model with $\beta=0$. The out-of-sample statistics that we calculate are then given by:

$$
\begin{aligned}
R^{2} & =1-\frac{M S E_{U}}{M S E_{R}}, \\
E N C-N E W & =\frac{\sum_{t=1}^{T}\left(\hat{\varepsilon}_{R, t+1}^{2}-\hat{\varepsilon}_{R, t+1} \times \hat{\varepsilon}_{U, t+1}\right)}{M S E_{U}}, \\
M S E-F & =T \times \frac{M S E_{R}-M S E_{U}}{M S E_{U}},
\end{aligned}
$$

where $M S E_{U}$ is the mean squared error of the unrestricted model, $M S E_{R}$ is the mean squared error of the restricted model, and $T$ is the number of out-of-sample forecasts.

The OOS $R^{2}$ in Eq. (4) measures the percentage reduction (or increase) in the mean squared forecast error of the unrestricted model compared to the mean squared forecast error of the historical mean model. A positive OOS $R^{2}$ therefore implies that the unrestricted forecasting model generates smaller forecast errors than the restricted forecasting model (the historical mean model). We rely on three forecast comparison tests. Clark and McCracken's (2001) ENC$N E W$ statistic, defined in Eq. (5), tests the null hypothesis that the restricted forecasting model encompasses the unrestricted forecasting model. McCracken's (2007) MSE-F statistic, defined in Eq. (6), tests the null hypothesis that the restricted forecasting model has a mean squared error that is less than, or equal to, that of the unrestricted forecasting model. Both the $E N C$ $N E W$ and $M S E-F$ statistics have non-standard distributions, and we use the asymptotically valid critical values provided by Clark and McCracken (2001). Finally, we checked our results using the Clark and West (2007) statistic for which the standard normal distribution is a good approximation asymptotically. We use Newey-West standard errors and label the test $t(N W)$ in the tables. The results are qualitatively similar if using OLS standard errors instead of NW standard errors. 


\section{Appendix C. Extraction of the surplus consumption ratio.}

First, we estimate $g$ and $\sigma_{c}^{2}$ from:

$$
\triangle c_{t+1}=g+v_{t+1}, \quad v_{t+1} \sim \operatorname{niid}\left(0, \sigma_{c}^{2}\right)
$$

where $\triangle c_{t+1}$ is log consumption growth. This regression gives us a series of innovations to consumption growth $v_{t+1}$, which we use to generate the surplus consumption ratio:

$$
s_{t+1}=(1-\phi) \bar{s}+\phi s_{t}+\lambda\left(s_{t}\right) v_{t+1}
$$

where

$$
\begin{gathered}
\lambda\left(s_{t}\right)=\left\{\begin{array}{cc}
\frac{1}{\bar{S}} \sqrt{1-2\left(s_{t}-\bar{s}\right)} & \text { if } s_{t} \leq s_{\max } \\
0 & \text { else }
\end{array}\right\} \\
\bar{S}=\sigma_{c} \sqrt{\frac{\gamma}{1-\phi}}, \quad s_{\max }=\bar{s}+\frac{1}{2}\left(1-\bar{S}^{2}\right), \quad \bar{s}=\log (\bar{S}) .
\end{gathered}
$$

We have used $\gamma=2$ and $\phi=0.87^{1 / 4}=0.966$, like in Campbell and Cochrane (1999).

The initial value of the surplus consumption ratio is the steady state value: $s_{0}=\bar{s}$. The next values thus become:

$$
\begin{aligned}
& s_{1}=(1-\phi) \bar{s}+\phi \bar{s}+\lambda(\bar{s}) v_{1} \\
& s_{2}=(1-\phi) \bar{s}+\phi s_{1}+\lambda\left(s_{1}\right) v_{2}
\end{aligned}
$$

In our forecast regressions, we use $S_{t}=\exp \left(s_{t}\right)$. We generate a quarterly time series for $S_{t}$, which we afterwards split into quarters. An alternative procedure would be to calculate a surplus consumption ratio based solely on $\mathrm{Q} 4$ shocks: $\triangle c_{t+1}^{4}=g^{4}+v_{t+1}^{4}$. This would give even more forecasting power, as we would then only use fourth-quarter growth rates. Instead we have followed Campbell and Cochrane (1999) precisely and split into quarters afterwards. In this sense, our results are conservative. 